\title{
An agent-based transportation impact sketch planning (TISP) model system
}

\author{
Ayad A. Hammadi (corresponding author) \\ University of Toronto \\ ayad.hammadi@mail.utoronto.ca
}

\author{
Eric J. Miller \\ University of Toronto \\ eric.miller@utoronto.ca
}

\begin{abstract}
A traffic impact sketch planning (TISP) model is presented for the estimation of the likely travel demand generated by a major landuse development or redevelopment project. The proposed approach overcomes the problems with the non-behavioral transportationrelated studies used in practice for assessing the development design impacts on the local transportation system. The architectural design of the development, in terms of the number and type of dwellings, by number of bedrooms per unit, and the land-use categories of the nonresidential floorspace, are reflected in the TISP model through an integrated population and employment synthesis approach. The population synthesis enables the feasible deployment of an agent-based microsimulation (ABM) model system of daily activity and travel demand for a quick, efficient, and detailed assessment of the transportation impacts of a proposed neighborhood or development. The approach is not restricted to a certain type of dataset of the control variables for the geographic location of the development. Datasets for different geographic dimensions of the study area, with some common control variables, are merged and cascaded into a synthesized, disaggregate population of resident persons, households and jobs.

The prototype implementation of the TISP model is for Waterfront Toronto's Bayside Development Phase 2, using the operational TASHAbased GTAModel V4.1 ABM travel demand model system. While conventional transportation studies focus on the assessment of the local traffic impacts in the immediate surroundings of the development, the TISP model investigates and assesses many transportationrelated impacts in the district, city, and region for both residents and nonresidents of the development. TISP model analysis includes the overall spatiotemporal trips distribution generated by the residents and nonresidents of the development for the auto and non-auto mobility systems and the simulated agent's diurnal peaking travel times. The model results are compared with the trips estimates by a prior project traffic impact study and the Institute of Transportation Engineers (ITE) Trip Generation Manual (TGM) rates of weekday trips for the relevant land uses. Future extensions and improvements of the model including the generalization and full automation of the model and the bi-level macro-micro representation of the transportation network are also discussed.
\end{abstract}

\section{Article history:}

Received: July 28, 2020

Received in revised form:

October 16, 2020

Accepted: October 19, 2020

Available online: February 10, 2021

Copyright 2021 Ayad A. Hammadi \& Eric J. Miller

http://dx.doi.org/10.5198/jtlu.2021.1863

ISSN: 1938-7849 | Licensed under the Creative Commons Attribution - Noncommercial License 4.0

The Journal of Transport and Land Use is the official journal of the World Society for Transport and Land Use (WSTLUR) and is published and sponsored by the University of Minnesota Center for Transportation Studies. 


\section{Introduction}

The transportation-related impacts of a new major development site, whether it be a downtown redevelopment precinct or a suburban greenfield development, are a matter of great planning importance. The impacts of interest may include: trips generated, commute mode shares, roadway congestion levels, transit service requirements, vehicle kilometers travelled ( $V K T$ ), energy consumption, greenhouse gas $(G H G)$ and pollution emissions, equity and accessibility impacts, active transportation usage (walking and cycling), etc. Despite the importance of these impacts for development site design and, in particular, how these impacts might vary positively or negatively as a function of the site design, modelling tools to assess these impacts are generally not optimized to address these questions, nor are they generally used during the site design process.

Considerable interest exists in the design of medium-to-high density, mixed-use neighborhoods, with strong assumptions that such neighborhoods generate more sustainable and beneficial transportation outcomes. But the actual transportation outcomes that can be expected to result from a specific design are rarely estimated during the design process per se. Two general approaches currently exist for assessing neighborhood design impacts on travel demand and transportation system performance:

1) Traffic impact studies (TIS ), which use very simplified techniques (for example, the ITE-TGM) to estimate the traffic generated to and from a new development site (such as a shopping mall or a new residential subdivision). These methods are generally inadequate to provide detailed metrics of transportation impacts and are generally inconsistent with more formal and comprehensive models of travel demand.

2) Comprehensive, regional travel demand model systems which generate a wide range of impacts associated with new developments. They are also able to account for the development site's spatial location and interactions with the surrounding urban fabric. They are, however, also not without their limitations for this purpose. Traditional issues with such large-scale, regional models in this context include:

2.1) They must be run for the entire urban region in order to estimate the impacts of the new development, which is inevitably a relatively minor addition to the overall region, both in terms of new population and employment, and economic and travel activities.

2.2) Their traffic zone-based structure may be overly aggregated to be sufficiently sensitive to small-area neighborhood and local area transportation network design details. Thus, these models are not directly sensitive to the actual physical design of the development site (for example, types of residential units, etc.), only the net population and employment projected for the site.

2.3) They require specialized software (for example, EMME, XTMF), special preparation of their input files, large computing capabilities to run, and long model system run times. Therefore, they cannot be readily used by non-specialists for direct integration into an iterative design process for quick comparative assessments of the likely transportation impacts of alternative neighborhood designs.

Agent-based microsimulation $(A B M)$ models of daily activity and travel demand have the potential to address many of these concerns, particularly if they are computationally efficient with minimized run times. In an ABM framework, the land-use is converted into equivalent activity systems, as shown in Figure 1, to facilitate the mathematical modeling (simulation) of their interaction and the estimation of transportation related impacts. It is a focal point in urban simulation models to approximate the spatiotemporal distribution of the socioeconomic activity systems for travel demand and behavior estimation. However, for a site-specific large development (for example, a precinct or neighborhood 
development) the concern is whether the generated activities, and residents' and non-residents' travelrelated behavior, by the new development are compatible with the transportation system and facilities at site. The objective of this article is to demonstrate the feasibility of developing a Transportation Impact Sketch Planning (TISP) procedure that makes use of such an $A B M$ model system in a manner that addresses the three concerns listed above of using a comprehensive big regional model. More specifically, the proposed TISP model permits quick but very detailed assessment of the transportation impacts of a proposed new neighborhood (or precinct or district; these terms are used interchangeably herein) physical design. That is, the intent is to be able to translate a proposed architectural plan for a precinct into projected population and employment for the district as described in Section 6. The $A B M$ model system then estimates typical 24-hour weekday travel to, from and within the district, along with a range of travel-related performance measures (greenhouse gas emissions, auto VKT, transit PKT, mode shares, local street congestion levels, etc.).

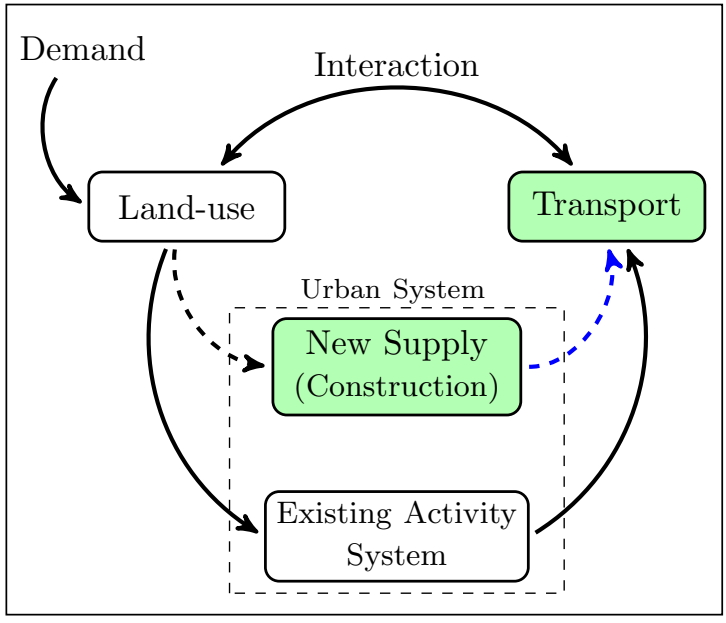

Figure 1. Context of land-use transport interaction with new supply

Section 2 of the article presents a high-level literature review of population synthesis (in Section 2.1) and transportation impact sketch planning (in Section 2.2). Sketch planning in the context of travel demand forecasting is required to enable rapid exploration and analysis of a variety of land-use development alternatives and their likely transportation related impacts. Section 2.2 also compares the pros and cons of the different sketch planning approaches and the advantages of using $A B M$ models over non-simulation trip-based approaches. Section 3 presents the $A B M$ approach for sketch planning and discusses the short-comings of the ITE-TGM and the conventional four-step approaches in comparison to the extent of improvements offered by $A B M$ models. The section also assesses the use of the TASHA-GTAModel model system for transportation impact sketch planning against the issues of using comprehensive, regional travel demand models as discussed in Section 1. Section 4 provides an overview of the GTAModel V4.1 model system and its applications, as an $A B M$ activity and travel demand forecasting model system, in the TISP context. It provides (in Section 4.1) an overview of the GTAModel V4.1 model and its TASHA core, which generates daily out-of-home trips for each person in each household. It also lists (in Section 4.2) the required extensions to the GTAModel for implementing the TISP model. Section 5 discusses the theoretical bases of the proposed TISP procedure and its novel feature in integrating the architectural features of the new land-use with the transportation related impacts. To demonstrate the usefulness of the proposed procedure, a development precinct in the Toronto Waterfront area (Bayside Phase-2 development), and its associated data, is described in Section 5.1 as an empirical case study. Section 6 describes the population and employment synthesis procedures, 
which are crucial in transitioning the new development features into an equivalent activity system. The section also presents the results of the population and employment synthesis for the case study in terms of Household and Person socioeconomic attributes, that are likely to occupy the development dwellings upon completion and the jobs list for the nonresidential floor space of the development. Section 7 presents and illustrates the results of the application of the prototype TISP to the case study precinct for the generated trips by Bayside development. The residents' trips generated by the TASHA microsimulation approach are compared with the total trips calculated using the following methods: (1) trip rates and regression equations of the ITE's Trip Generation Manual (ITE, 2017), which is widely used in practice for estimating number of trips, and (2) the vehicle trip rates used in the development traffic impact study. Finally, Section 8 concludes the paper with a summary of findings and discussion of next steps in the evolution of the TISP procedure.

\section{$2 \quad$ Literature review}

\subsection{Population synthesis}

Population synthesis in the context of land-use transport interaction is the process of fitting agents, with controlled statistical attributes, to the activity system of an urban area to enable the use of ABM modelling in estimating the transportation related impacts (travel demand and behavior) of the simulated activity system. It uses different numerical approximation methods and data fitting procedures to produce disaggregated micro datasets of the synthesized agents (households, persons, job lists, etc.) without violating privacy protection protocols. As shown in Figure 2, a typical population synthesis process uses two datasets; that is, a sample disaggregated dataset, which could be a representative questionnaire survey of a portion of the population in the study area, and marginals (totals) of population attributes from census information, with which the sample is fused. The land-use characteristics; for example, housing characteristics in terms of type (apartment or house) and number of bedrooms for residential land-use, are sometimes included in the population synthesis process (as denoted by the solid lines in Figure 2) and sometimes they are not (as denoted by the dotted line in the figure). For the latter case, the landuse characteristics are generally reflected in the urban activity system layout; for example, origins and destinations of activities, and locations of residence or employment. ${ }^{1}$

\footnotetext{
1 The urban area TAZ zones, where the majority of trips are coming from and where they are going to, are representative of the types of land-use found in each particular area.
} 


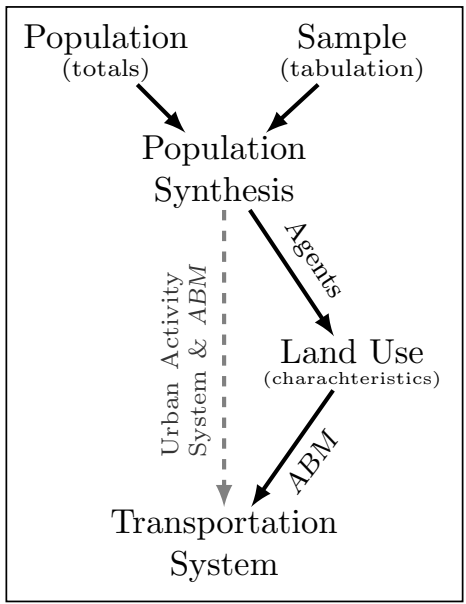

Figure 2. Population synthesis in the LUTI context

Perhaps the first population synthesis procedure ${ }^{2}$ was introduced by (Deming \& Stephan, 1940). They developed an iterative proportional fitting (IPF) procedure as an approximate method for solving three (or more) dimensional Lagrangian multipliers normal equations for estimating population cell counts of a cross-tabulation (joint-distribution) that fits known total characteristics' frequencies (marginal summaries) of the population. (Geman \& Geman, 1984) applied Gibbs' work on statistical mechanics of thermodynamics in image-processing models using a random field. This sampling method became to be known as Gibbs sampler. (Beckman, Baggerly, \& McKay, 1996) extended the IFP method to solving population synthesis problems for transportation modelling by adding a synthetic-reconstruction process. This synthesizing method, which is widely used by transportation agencies, allows for retaining the heterogeneous population attributes of small geographies; for example, Census Tract (CT) or Traffic Analysis Zone (TAZ) zones.

(Müller \& Axhausen, 2010) summarized the state of the art of population synthesis approaches, up to the time of their article. They asserted that "all [...population synthesis works] share two tasks: (a) adjustment of an initial population, taken from a past census or other survey data, to current constraints, and (b) selecting households and optionally assigning them to geographic areas." (Farooq, Bierlaire, Hurtubia, \& Flötteröd, 2013) proposed a Markov Chain Monte Carlo (MCMC) simulation approach for population synthesis to overcome the shortcomings in fitting-based procedures, such as an over reliance on the accuracy of the sample contingency tables and losing population heterogeneity. (Zhuge, Li, $\mathrm{Ku}, \mathrm{Gao}, \&$ Zhang, 2017) proposed a heuristic-based population synthesis method for transportation related applications as a counter view to the optimization notion associated with conventional population synthesis approaches. In fitting-based approaches the objective is to minimize the mean absolute percentage error of control variables, while (Zhuge et al., 2017) argues that the standard deviation of control variables is also crucial in some cases. They implemented their method in the medium-size city of Baoding in China.

\footnotetext{
2 It is said "perhaps" because Josiah Willard Gibbs in his 1878 book, On the Equilibrium of Heterogeneous Substances, formulated the case for synthesizing a mass when its substances are not independent. His formulation became known later as the Gibbs sampler.
} 


\subsection{Transportation impact sketch planning}

According to (Brand \& Manheim, 1973), sketch planning, in the context of travel demand forecasting, is "transportation analysis procedures that are simpler, faster, and cheaper than using forecasting systems in their entirety and that typically require less input detail and provide fewer output measures with more variability." Sketch planning models can "range from scaled-down conventional aggregate modelling suites of programs to ad hoc approaches developed from some simple ideas and assumptions" (Ortùzar $\&$ Wilumsen, 1990). However, according to Moeckel (2018):

Sketch planning models are rule-based and excellent for long-term visioning, because they [...] allow users to assess the development capacity of considered land use scenarios. [However,] such models do not model human behavior explicitly but develop rules for development interactions. ${ }^{3}$

The above description of the sketch planning models by (Moeckel, 2018) is based on his classification of land-use models into: rule-based, behavioral, and hybrid models as shown in Figure 3. He asserted that "rule-based models often define the term land use as land cover [and buildings alternatives /configurations], while mathematical models, [which are behavioral models,] tend to define land use as allocation of population and employment" (Moeckel, 2018, p. 11). While the rule-based models do not attempt to model human behavior, ${ }^{4}$ behavioral models, ${ }^{5}$ on the other hand, use behavioral theory to simulate human behavior at the expense of longer running time and data requirements. Hybrid models use elements from both rule-based and behavioral models. Sketch planning models are sometimes used as a preliminary modelling stage prior to a more advanced behavioral modelling stage. It is clear that sketch planning models in the context of (Moeckel, 2018) land-use models classification, as illustrated in Figure 3, are concerned with land-use distribution; for example, in a regional planning model, and do not reflect the land-use transport interaction. Therefore, this description does not fit the definition and purpose of the transport sketch planning used in this article where the goal is to reasonably estimate the likely transport impacts by land development scenarios.

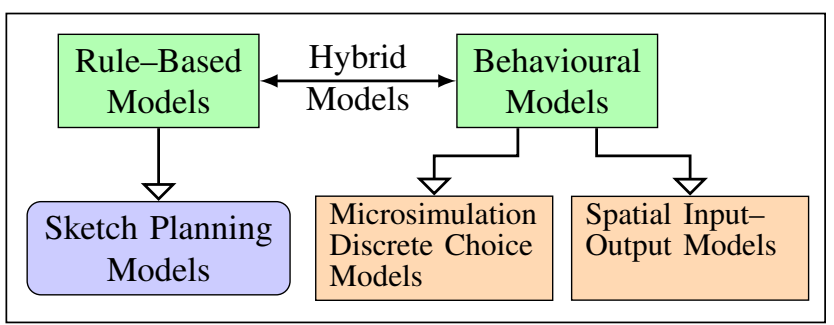

Figure 3. (Moeckel, 2018) Land-use model type classification redrawn and modified based on Figure 1-2 in (Moeckel, 2018)

Transportation planning and travel demand forecasting can be based on several main approaches. Travel demand modelling, however, is a complex process because of the derived demand (trip purpose) nature of the travel behavior, the socioeconomic attributes of the travelers, the land-use profile (for example, mixed-use development) of the O-D zones, and the different characteristics (price, LOS, volume, speed, etc.) of transportation systems (auto, transit, etc.) usually available to a potential traveler in an urban area (Morlok, 1978, p. 418,419). As a result, transportation planning processes have shifted to activity-based approaches where microscopic simulation / analytical models of human behavior are

\footnotetext{
3 "Examples of sketch planning models include CommunityViz, Envision Tomorrow, UPlan" (Moeckel, 2018) and IPLACE3S.

${ }_{4}$ An example of a rule used in rule-based models is that "areas near transit stations would be developed before other areas are developed" (Moeckel, 2018, p. 26).

5 Behavioral models are further categorized, as shown in Figure 3, into microsimulation discrete choice models (for example, Silo and UrbanSim) and spatial input-output models (for example, PECAS and TRANUS.) These models are not discussed here because the focus is on sketch planning models.
} 
constructed. These models, which are mainly based on human factor rules (statistically significant rules), generate the likely travel behavior of individuals (persons and households) based on their experience (historical-usage) of transportation systems and how they make decisions and how all their decisions interact and influence each other (Becker, Schneider, \& Schwartzmann, 1991, p. 569).

Despite the shift toward modelling individuals' travel behavior, "planning process needs require predictions of travel flow at a level of aggregation which is relevant to the policies under study" (Koppelman, 1975). Precision of the aggregated individuals' travel demand depends on the disaggregate choice model, distribution of the independent variables, and the aggregation procedure. This is in contrast to the aggregate predictions, of multivariate regression or cross-classification (category) analyses, which are based on an aggregate description of the geographic area (CT or TAZ zones) socioeconomic attributes and characteristics of the transportation system. Aggregation procedures which are based on behavioral theory or models reflect the relationship between the group travel behavior, which is the objective of travel demand forecasting, and individuals' travel choices (Koppelman, 1975). However, as discussed in Section 2.1 above, disaggregate data for the predicted group population is mostly unavailable or restricted due to statistical disclosure control. It is the standard practice for population behavioral modelling or simulation in transportation related analyses to generate the population socioeconomic attributes using different population synthesis and sampling techniques. Therefore, precision of the travel behavior estimation using population (micro)simulation approaches, based on choice model, is highly dependent on the procedure used in generating (synthesizing) the population attributes of interest from the sample data.

(Kaplan, Gur, \& Vyas, 1984) developed an advanced sketch-planning model package utilizing state-of-the-art household-based, disaggregate travel demand models for mode and destination choices as shown in Figure 4. The model package is used to estimate the impacts of various alternative urban transportation energy-conservation policies for a horizon period of 15 years. They implemented a scenario approach to account for the high uncertainty of future conditions. The core of their model is a computer package, as shown in Figure 4(b), which consists of a sequence of disaggregate modules "that estimate aggregate [district-to-district] travel demand through a random sampling enumeration process." What is interesting about the (Kaplan et al., 1984) model package is that they incorporated a (IPF) population synthesis approach, as shown in Figure 4(a), as a model operator for testing different scenario-specific populations and work travel behavior (pattern) for the geographic area under study. The IPF process modifies $\mathrm{HH}$ expansion weights to reflect future populations and work trip travel patterns.

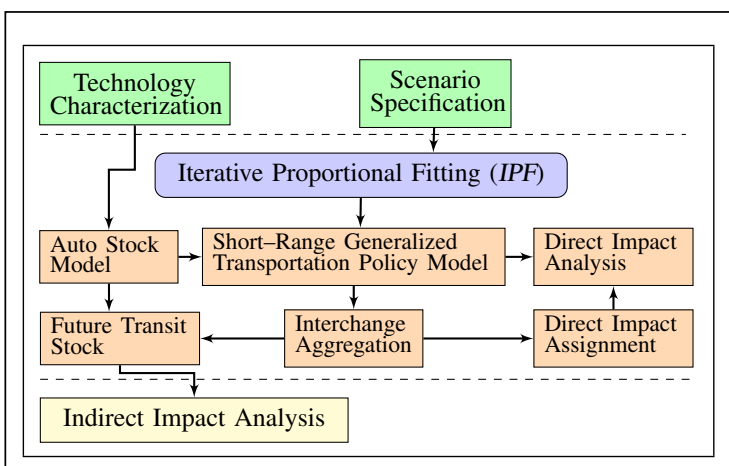

(a) Analysis Process

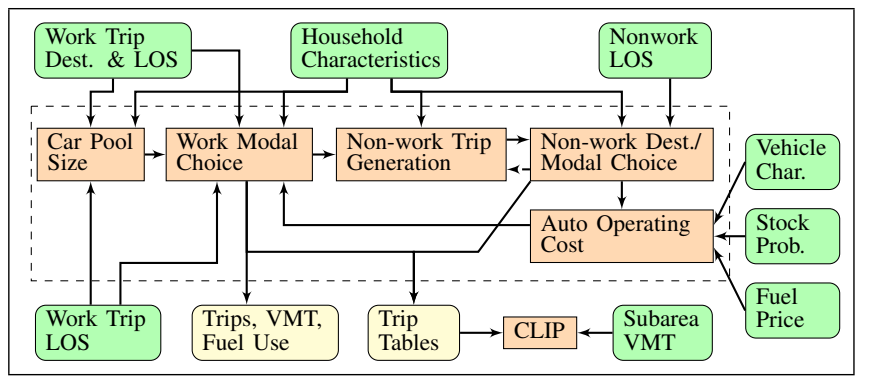

(b) Computer Model

Figure 4. (Kaplan, et al., 1984) Analysis process and computer model for urban transportation policy analysis 
Not many of the transportation sketch planning models in the 1970s and 80s are advanced as the (Kaplan et al., 1984) model package shown in Figure 4. According to (Ortùzar \& Wilumsen, 1990) "most sketch planning methods rely considerably on the transfer of parameters and relationships from one area or country to another [where] only certain aspects of the models are made location dependent $[. .$.$] " The widely used document in practice for trip generation data for transportation (vehicular)$ impact analysis is the ITE Trip Generation Manual (TGM), which was first published in 1976.6 The ITE-TGM is basically based on the transfer of (vehicular) trip rates, and other regression-fitted relationships, for 176 land-uses within 10 major land-use categories in its 2017, 10 ${ }^{\text {th }}$ edition (Trip Generation Manual, 2017). These sketch planning models, based on transferable trip rates and relationships, are "relying heavily on assumed regularities in human behavior in the transport field" (Ortùzar \& Wilumsen., 1990).

In contrast to transferring trip rates and relationships, there is a research line which focuses on developing sketch planning or estimating models in terms of statistical relationships to express number of trips or commute mode shares in terms of retrospective explanatory variables. For example, (Schneider, $\mathrm{Hu}, \&$ Stefanich, 2019) developed a fractional multinomial logit (FMNL) model, which uses a logistic function to estimate the work commute mode shares based on aggregated neighborhood level data of 5,000 randomly selected, non-adjacent, US national CTs. ${ }^{7}$ Their model incorporates 24 explanatory variables represent the neighborhood and regional characteristics, as well as socioeconomic and ethnicity variables. Despite that their FMNL model was validated using a separate set of 1,000 CTs, its application to the seven-county Milwaukee metropolitan region's land-use transport forecasting plan for 2050 revealed several limitations of this approach. This is mainly because the structure of a MNL model, like the FMNL model, is based on cross-sectional data and therefore it does not imply direct causation between explanatory and dependent variables (Schneider et al., 2019, p. 925).

The quick response system (QRS II), ${ }^{8}$ developed and maintained by Alan J. Horowitz, which is based on the work of (Sosslau, Hassam, Carter, \& Wickstorm, 1978) and (Martin \& Mcguckin, 1998), is an operational model system for quick urban travel demand forecasting. However, the trip generation in the QRS is based on transferable trip rates and cross classification methods for different trip purposes; that is, home-based work (HBW), home-based non-work (HBNW), and non-home-based (NHB) trips. ${ }^{9}$ The QRS model does not implement (micro)simulation techniques for generating activities systems, and their associated likely travel demand and behavior, based on established behavioral rules for the urban agents (household, persons, employment, etc.) and their attributes (as in an ABM model system).$^{10}$ It utilizes different trip table refinements methods for quick response travel forecasting; see for example (Horowitz, 2005). Therefore, such a quick response model system, although it could be useful in providing timely quick responses to forecast urban travel demand and behavior in contrast to the comprehensive regional models, it lacks the behavioral characteristics of the ABM model systems which provide a wide range of travel related impacts of different urban development and transportation systems policies.

In contrast to the QRS model, which does not utilize statistical behavioral rules for travel demand estimation, (Zhang, et al., 2013) developed "a framework that integrates agent-based travel behavior models with large-scale [dynamic] traffic simulation ${ }^{11}$ to capture the regional impacts of new develop-

6 The most recent print of the TGM manual is the $10^{\text {th }}$ edition, which was published in 2017 in two volumes with more than 3,000 pages.

${ }^{7}$ Schneider et al. (2019) retrieved their data from the American Community Survey (ACS) journey-to-work dataset, "which is the only data source that provides travel data at the neighbourhood level for the entire US."

8 http://ajhassoc.com/.

9 For full list of features, methods used by the QRS model, and its limitations see: http://ajhassoc.com/index.php/features/.

${ }^{10}$ However, it is mentioned on the QRS features' webpage that it can be interfaced with activity-based (ABM) demand models and freight microsimulation models.

${ }^{11}$ They used TransModeler software for the traffic microsimulation model which has a well-developed interface with the geographical information system (GIS) (Zhang, et al., 2013). 
ment." Their integrated framework is based on the notion that travelers' behavior is guided by a series of logical evaluation rather than the normative approach of utility-based maximization. However, they limited the travel behavior microsimulation model of their framework to the agent-based departure time choice problem ${ }^{12}$ to enhance the conventional four-step models by adding agent-based travel demand submodels. ${ }^{13}$ (Zhang, et al., 2013) applied their integrated framework to estimate the residents' departure time related impacts of several proposed new developments at the I-270/I-495/I-95 corridor in the north Washington, DC metropolitan area on the entire road network in the study area. The proposed developments at I-270 corridor will add 5,750 residences in the horizon of 25-30 years and are expected to attract 52,500 jobs.

However, for demonstrating the application of their framework the authors assumed that the proposed "developments will generate 30\% more travel demand" which will change the traffic pattern and peak spreading in the region and "motivate some travelers to adjust their departure time accordingly" (Zhang, et al., 2013, p.100). The authors did not assert a justification for their assumption for the travel demand estimation of the proposed developments and this is clearly a shortage in this study. (Zhang, et al., 2013) could, in the author's opinion, exerted extra effort to make a basic estimation of the total travel demand of the proposed developments using; for example, the available trip generation rates from the local municipalities or use the ITE TGM general trip generation rates for the corresponding land uses and urban/suburban contexts of the study area. ${ }^{14}$ However, the authors' focus was on estimating, calibrating, and simulating the traffic counts on the road network links. This clearly brings forward the need for advanced agent-based microsimulation (ABM) models for estimating the travel demand and behavior of travelers based on their corresponding individual attributes and the opportunities in their environment and this is discussed in the next section.

\section{$3 \quad$ An agent-based approach for sketch planning}

Traditional "traffic impact" models, typified by the ITE Trip Generation Manual (TGM) procedures, suffer from numerous short-comings, including:

1. They are very vehicle-based in their focus, providing little or no information concerning person trips by transit and active modes of travel.

2. They only predict trip generation (trips to/from the study site), not destination, mode or route choices. They thus, at best, only provide some assessment of roadway impacts on the streets immediately surrounding the study site.

3. They are socio-economically very aggregate and so cannot differentiate among impacts on different types of trip-makers or account for differences in trip-making behavior among these different users.

4. They are temporally aggregate, at best differentiating between peak-period and all-day trip estimates. They, therefore, do not provide detail profiles of study area trip-making over the course of a typical day.

5. They tend to deal best with trip generation by nonresidential (i.e., commercial) land uses. They generally do not deal as well with residential trip generation.

6. They generally rely on aggregate, average trip rates compiled from a variety of diverse sources, which often are not representative of local area travel behavior.

\footnotetext{
${ }^{12}$ It has been a long time argument that the time-of-day model is the missing fifth step in the four-stage approach of travel demand modelling (Hensher \& Button, 2000, p. 18) and it seems that (Zhang, et al., 2013) developed their travel behavior model by adding this fifth stage.

${ }^{13}$ Both the network supply and the travel behaviour models were calibrated using locally collected high-quality field data (Zhang, et al., 2013).

${ }^{14}$ In an urban context it is mostly the case that the ITE TGM trip generation rates need to be adjusted using an auto modal split factor for the study area to account for multimodal transport system.
} 
Conventional four-step, trip-based travel demand models are not suitable for use in development site impact analyses for the reasons already listed in Section 1. Agent-based microsimulation (ABM) models of activity/travel behavior, on the other hand potentially can improve upon the limitations of both TGM-type methods and four-step demand models. Potential advantages of such models relative to TGM-type methods include:

1. They are multi-modal, generating person trips by all modes of travel (some of which eventually turn into vehicle trips).

2. They generate a complete picture of travel: generation, distribution, mode choice and route choice (to use four-step terminology) for all trips for all purposes, rather than just "point" estimates of trip productions and attractions.

3. They are socio-economically disaggregated, generating trips for each person individually within the study area. Thus, differences in behavior and impacts experienced by different types of people (by income, employment status, age, etc.) are explicitly identified.

4. Although differences exist among different model systems, ABM models generally are temporally disaggregate, generating trips over the course of the entire day, so that the transportation impacts (local congestion, emissions, etc.) can be temporally assessed.

5. Such models are inevitably calibrated for the urban region for which the model has been developed, and so should be representative of local area travel behavior.

The extent to which an ABM travel demand model system can improve upon the performance of traditional trip-based models depends largely on the model system's software design that determines: (a) its computational run times and (b) its flexibility and ease of use. Certainly, most currently operational or quasi-operational activity-based models have run times that are as long as, or, often, longer than, the four-step models that they have replaced. They also are difficult to set up and use and to adapt to new applications such as this one. Thus, they are generally as cumbersome and inappropriate to use for sketch planning as their trip-based predecessors.

An exception to these generalizations (at least to a large extent), is the TASHA ${ }^{15}$-based GTAModel V4.1 ABM travel demand model system (as presented in section 4.1) in operational use in the Greater Toronto-Hamilton Area (GTHA). Assessing this model system against the three issues raised in Section 1, the following are noted:

1. GTAModel does need to be run for the entire GTHA in order to assess travel behavior of a new precinct. The key advantage of GTAModel relative to other known model systems, however, is its very quick run times. While it certainly cannot provide results "in real time", a fully-equilibrated 24-hour travel forecast for an urban region of 7+ million people can be generated with a 1-3 hour run time, depending on the computer used and the amount of post-processing of model run outputs requested. ${ }^{16}$ Thus, multiple precinct designs can be tested and analyzed within a single day (or less, if multiple runs are undertaken in a cluster or cloud computing environment). This is still not ideal for a sketch-planning tool but is a significant advance over competing alternatives. The ABM structure of the model system also allows the travel impacts of the development precinct (i.e., trips to/from/within the precinct and other related performance measures) to be quickly extracted for user assessment.

2. While still zone-based in its spatial architecture, fine zone detail to represent the development

${ }^{15}$ TASHA stands for Travel Activity Scheduler for Household Agents. It was introduced by Miller and Roorda in 2003 under the name of Toronto Area Scheduling Model for Household Agents. The model uses a priori heuristic rules (rule-based method) to fit activities from (survey sample) weekday agenda in schedules of projects (container of activities) for interacting household members (Miller \& Roorda, 2003).

${ }^{16}$ It would be possible to reduce the regional study area being modelled within the TISP application so as to reduce run times further, but the effort required to do so was not judged to be worthwhile, given the current speed of the model system. 
precinct (down to the individual building if desired) can be readily added to the model system to capture spatial design details of the precinct. The agent-based nature of the model system will then generate trips to/from these small zones/buildings by the individuals living, working, shopping, etc. there.

3. As discussed further below (in particular, Section 4.2), a new feature added to GTAModel to support the TISP is extending its population and employment synthesis procedure so that it is directly sensitive to the actual physical design of the development site (e.g., types of residential units, etc.). This is a key contribution of TISP.

4. GTAModel is an application running within custom-software developed at the University of Toronto, XTMF (eXtensible Travel Modelling Framework), which has been explicitly designed to be flexibly and readily extended in a variety of ways. TISP is a good example of the usefulness of XTMF in that the extensions of GTAModel required to implement TISP were very simple to implement. XTMF also provides a powerful user interface that makes setting up and executing model runs and extracting run results straightforward, including for non-specialists.

5. The modified zone systems discussed in point 2 above, and associated edits to the road and transit networks still need to be locally revised (updated) by a user familiar with the network modeling software being used. This often need not be an overly onerous task, and once, the base network has been updated, it often is possible to test many precinct designs without requiring network recoding. Further discussion about the required updates to the local zone and network system at the development's site location is provided in Section 4.2.

\section{$4 \quad$ GTAModel V4.1 and its application in TISP}

\subsection{Overview of GTAModel}

GTAModel V4.1 is an ABM activity and travel demand forecasting model system that has been developed for the Greater Toronto-Hamilton Area (GTHA). It is currently in operational use (or is in the process of being adopted) by the Cities of Toronto, Mississauga, Brampton and Vaughan, and by the Regional Municipalities of Durham, Hamilton and Peel. Figure 5 provides a high-level overview of GTAModel. At its core is TASHA (Travel -Activity Scheduler for Household Agents), which generates daily out-of-home activity schedules for each person in each household within the GTHA, and the associated trips (organized within home- and non-home-based tours) to and from each out-of-home activity episode location. ${ }^{17}$

\footnotetext{
${ }^{17}$ Using a server equipped with CPU of "2x Intel Xeon E5-2698 v3" with 64 GB of RAM a full GTAModel run for the whole GTHA area takes around 1.5 hours. The population synthesis and the generation of the Household and Person sets are semiautomated in a separate spread sheets' (Excel) setup where the developed text (.csv) files are uploaded to the GTAModel as input files. $90 \%$ of the computation time of the GTAModel run is involved in road and traffic assignment by interfacing the GTAModel and EMME in the XTMF framework.
} 


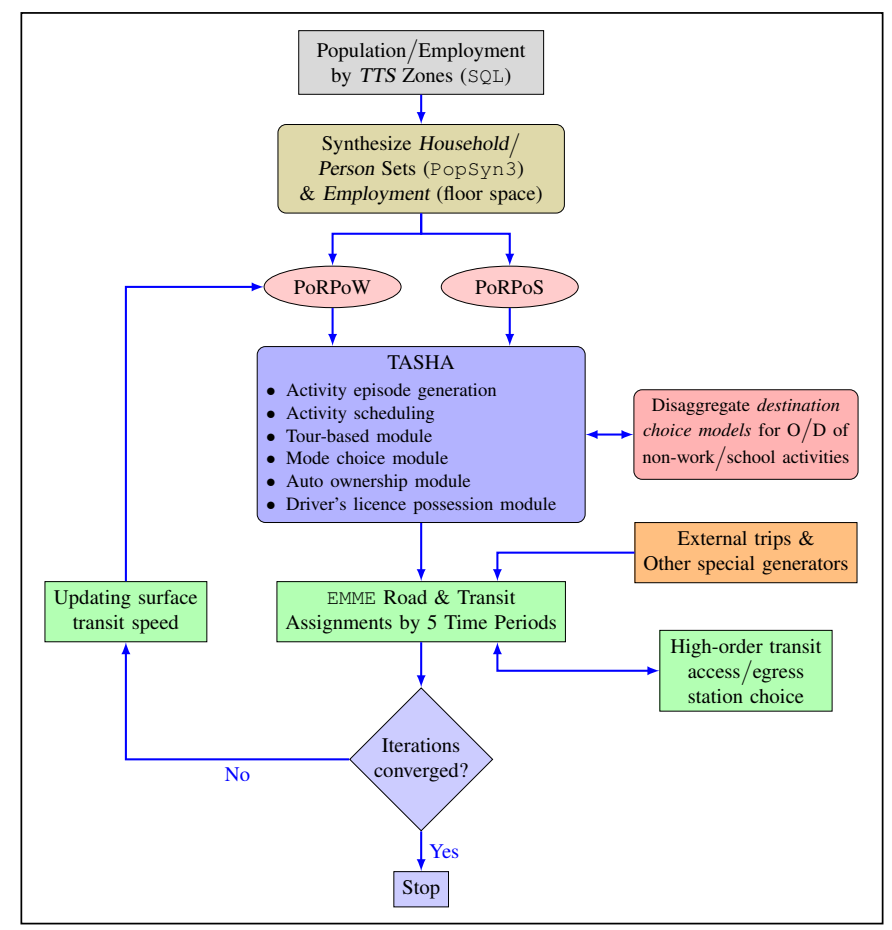

Figure 5. GTAModel V4.1 model system framework (PoRPoW: Place of Residence-Place of Work; PoRPoS: Place of Residence-Place of School)

TASHA is household-based in its organization so that it can explicitly account for household-level interactions with respect to: allocating household vehicles among competing drivers; organizing withinhousehold ridesharing; generating joint household activities (in additional to individuals' personal activities); and accounting for serve-dependent activities (e.g., taking young children to daycare, school, etc.). Once a person's daily activity schedule has been determined, the modes used to execute each trip within each tour are determined using a tour- based mode choice model that accounts for tour-level interactions; most notably, if a car leaves a household's driveway, it must eventually return home.

GTAModel is completely disaggregated in terms of generating trips for each person in the GTHA by purpose, mode and time of day. For practical operational implementation within the region, it uses the EMME ${ }^{18}$ commercial software package for doing road and transit assignments. This necessitates aggregating auto and transit trips into zone-based origin-destination $(\mathrm{O}-\mathrm{D})$ trip tables by time period for assignment. Five time periods are used: morning peak period, mid-day, afternoon peak period, evening and overnight. TASHA/GTAModel can, however interface with meso/microscopic simulators such as Aimsun ${ }^{19}$ and MATSim, ${ }^{20}$ albeit with significant increases in model system run times.

A key design principle in developing GTAModel is to maximize computational efficiency and flexibility in model specification and use. GTAModel is implemented as an application within XTMF (eXtensible Travel Modelling Framework). XTMF is a software package developed by the University of Toronto's Travel Modelling Group (TMG) to support transportation and land use model system development and application. It is a highly modular and flexible modeling environment in which a given model system (such as GTAModel) is built as a combination of previously programmed modules. This permits rapid prototyping of new systems and components, and very flexible extensions and

\footnotetext{
${ }^{18}$ https://www.inrosoftware.com/en/products/emme/

19 https://www.aimsun.com/. A GTAModel implementation using Aimsun's mesoscopic road assignment procedure is currently under development.

${ }^{20}$ https://www.matsim.org/. Research-based implementations of GTAModel with MATSim are being undertaken in Helsinki, Finland and Melbourne, Australia. University of Toronto MASc theses investigating this integration include Hao (2009) and Diogu (2019).
} 
improvements to a given model system over time. XTMF has also been programmed to maximize the computational efficiency of every operation, including parallelization of calculations whenever possible. TASHA is well documented in the academic literature; see, among others (Miller \& Roorda, 2002), (Miller, Roorda, \& Carrasco, 2005), (Roorda \& Miller, 2006), and (Roorda, Miller, \& Habib, 2008). GTAModel and XTMF documentation are available from the Traffic Modelling Group (TMG) in University of Toronto website. ${ }^{21}$

\subsection{GTAModel application in TISP}

The only extensions to GTAModel required to implement TISP were:

- Development of a modified population synthesis procedure that is driven by the precinct building types and dwelling unit sizes (number of bedroom) that can generate lists of synthesized household, person and employment sets for the study precinct. This procedure is described in Section 6.

- Modifications to the base GTHA traffic zone system and the representation of the modified road and transit network connecting to and within the precinct as shown in Figure 9.

The Bayside precinct resides within TAZ zone 29 in the base GTAModel zone system. This traffic zone was divided into 7 new zones to provide a more detailed spatial representation of the precinct at the level of individual buildings. Connections to the road and transit network for these new zones were coded accordingly and shown in Figure 9. Given these modifications, a full 2016 run of GTAModel V4.1 was generated with the new Bayside population and employment synthesized data and the local Bayside network modifications. Results from this run are summarized in Section 7.

The primary assumption underlying the use of the GTAModel model framework, as shown in Figure 5, to estimate the travel demand of Bayside development is that the new supply being analyzed represents an incremental addition to GTHA's urban form and the overall corresponding travel behavior. Therefore, the equilibrium conditions of the full GTAModel model run; that is, travel times, costs, etc., can still be achieved with the addition of the new development population, employment, and the local road network. Figure 6 shows an abstract class of the Bayside development for trips generation using TASHA and the synthesized Household, Person, and Employment sets, as discussed in Section 6. As shown in the figure, the synthesized population and employment of the new land-use are converted to episodes of activities using the projects scheduling agenda, as implemented in TASHA. The chained individual and household joint activities are then translated to travel episodes using the travel demand modelling framework of the GTAModel discussed in Section 4.1.

\footnotetext{
${ }^{21}$ https://tmg.utoronto.ca/doc/1.4/
} 


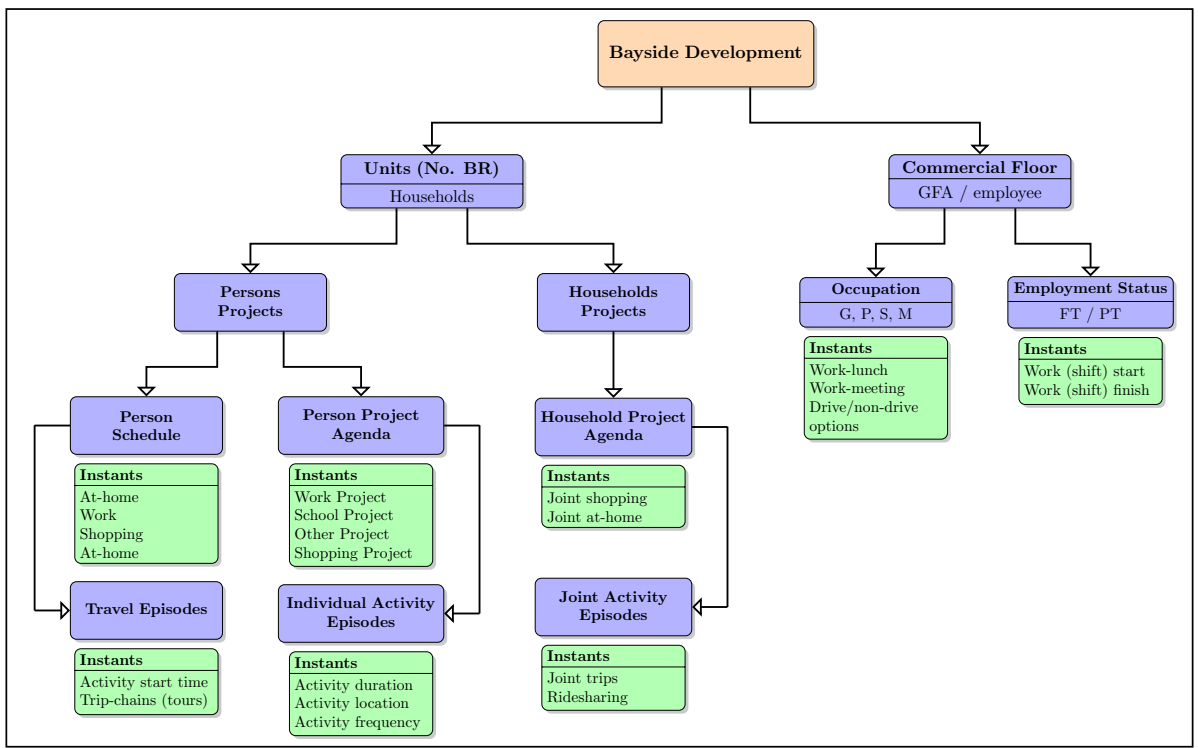

Figure 6. Abstract class of Bayside development for microsimulating activity based trip generation (Note: No. BR is not used in the GTAModel V4.1)

The trip-generation estimates presented in this paper are only for the new development of Bayside phase-2, although the fully equilibrated GTAModel was executed for all the (GTHA) area for the base year of 2016, as shown in Figure 5. This fits within an overall modelling context of the land-use transport interaction, but with the main interest in modelling the impact of new supply, rather than the existing activities, of the land-use as illustrated in Figure 1.

\section{Framework of transportation impact sketch planning (TISP) model}

As shown in Figure 7, the TISP model takes as its starting input a proposed physical (architectural) design of the development site in terms of the proposed:

- Number of residential units by structure type (apartment, single-family houses, etc.) and size (studio, one-bedroom, etc.).

- Amount of commercial floorspace by type (retail, office, etc.).

- Local street and transportation network design (by mode).

The first key step in the process is to convert this physical design into a synthesized population of persons, households, and employment by type. While population synthesis methods are common in best-practice travel demand models, they generally do not take the actual neighborhood physical design as their starting point. Thus, incorporation of housing unit type and size within the population synthesis process is novel and a somewhat challenging task. The procedure adopted in this case study is described in Section 6. The number of jobs (by occupation type) also needs to be synthesized from the amount of commercial retail floorspace (by type). Employment synthesis is not nearly as well-examined in the transportation modelling literature as population synthesis. Section 6 also discusses the simple procedure adopted for this purpose in this case study.

Once the neighborhood resident population and employment have been synthesized, the second major step in the TISP process is to estimate the daily weekday trips, by mode, purpose and time of day, to, from and within the development site, for both site residents and non-resident visitors. These trips 
are "assigned" to the multi-modal network serving the neighborhood to assess local area congestion etc. A suite of performance measures are provided to the user to help assess the positive and negative impacts of the design. Impacts from alternative designs (more housing, less retail; different mixes of housing types; etc.) can then be compared. As already noted in the previous sub-section, in this study, the agent/ activity-based microsimulation travel demand forecasting system that is in operational use in the Greater Toronto-Hamilton Area (GTHA), GTAModel V4.1, is used.

A key (and novel) feature of the proposed model is its integrated nature with the characteristics of the architectural design (master plan) of the new or existing development. The population synthesis procedure translates the dwelling units, by their number of bedrooms, into households and persons who are most likely to occupy the units based on their attributes and the development's location. This process establishes a specific link between the features of the existing or intended land-use, with its geographic location, and the generated activities and travel behavior of the residents. The employment synthesis for the nonresidential floor space determines the jobs that are likely to be generated by the development and therefore the travel behavior of the non-residents to, from and within the area. The generated population and employment are directly uploaded to the travel simulation framework (GTAModel) for estimating the trips generated and their spatiotemporal distribution, with travel behavior attributes related to the location of the development. The model procedure gives an endogenous behavioral aspect to the process of estimating the traffic and travel impact of the development rather than using an exogenous fixed trip rate that may or may not represent the actual travel behavior.

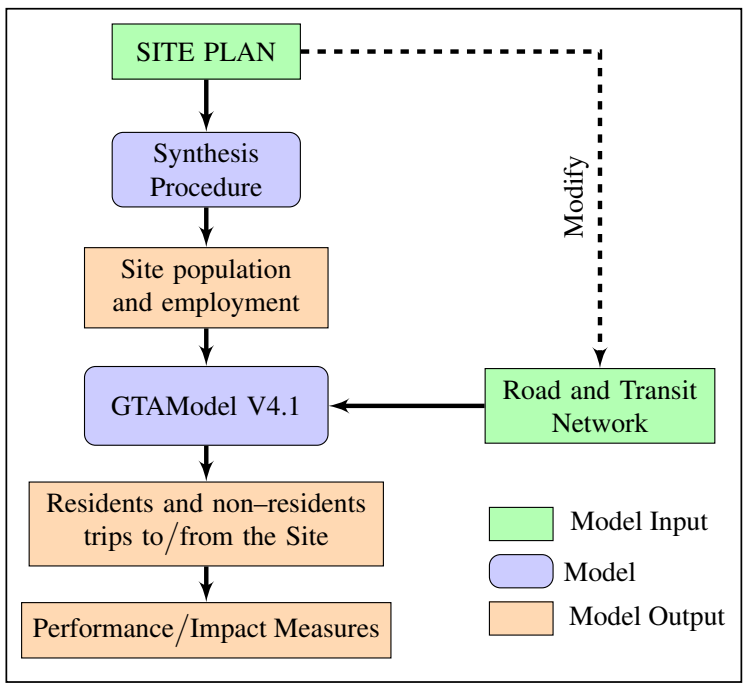

Figure 7. The TISP modeling process

\subsection{The Bayside case study}

The case study area for this analysis is Waterfront Toronto's Bayside Development Phase 2, located in Planning District 1 (PD1) and Census Tract 535001017.00 in the City of Toronto downtown, as shown in Figure 8. It consists of five residential and two commercial mid-rise buildings located on 3.2 hectares of post-industrial brownfield lands (Figures 8 and 9). 


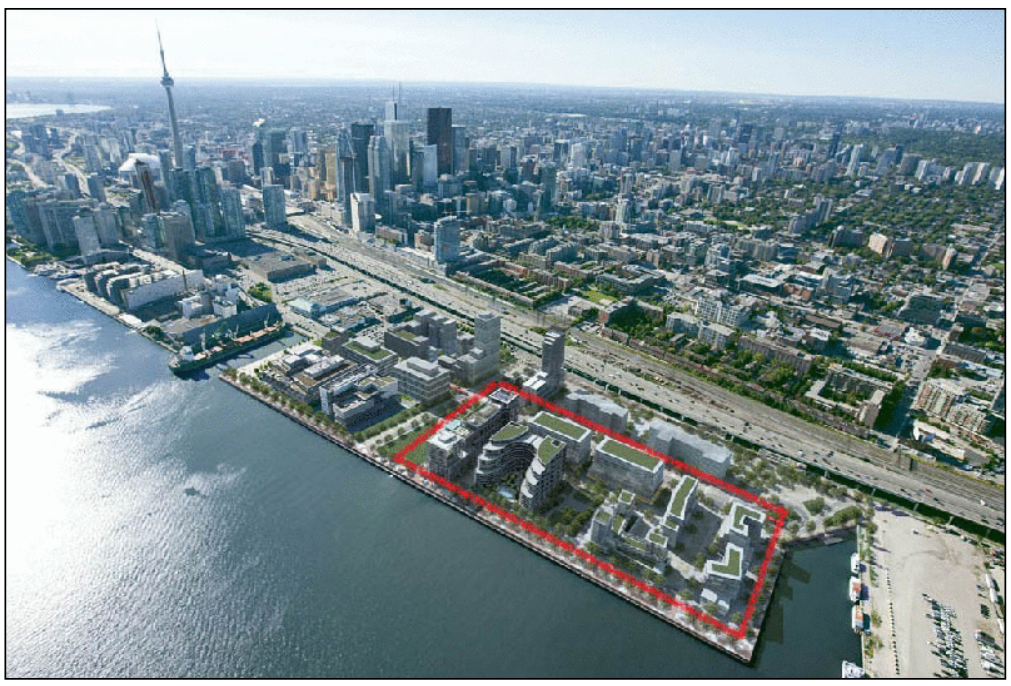

Figure 8. Bayside precinct within waterfront Toronto lands and downtown (Source: https://betakit.com/alphabet-investing-62-million-in-sidewalk-labs-toronto-site/)

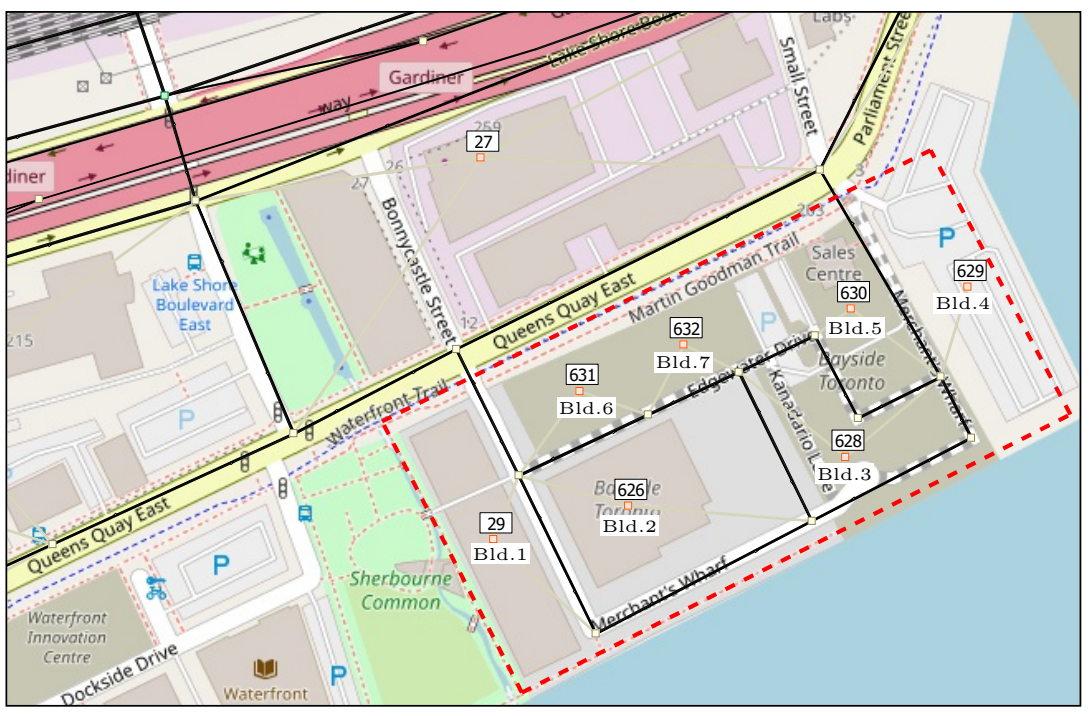

Figure 9. The Bayside precinct EMME network, TAZ zones, and buildings numbers

(Numbers in boxes represent TAZ zones numbers in EMME network and the labels (e.g. Bld.2) represent Bayside phase-2 development buildings numbers) 
Table 1. Statistics of Bayside precinct buildings

\begin{tabular}{|c|c|c|c|c|c|c|c|c|c|}
\hline Address & 15 Merchants & 262 Queens & 118 Merchants & 155 Merchants & \multicolumn{3}{|c|}{261 Queens Quay E } & \multirow{2}{*}{ Totals } & \multirow{2}{*}{ 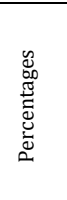 } \\
\hline TAZ Zone & 29 & 626 & 628 & 629 & 630 & 631 & 632 & & \\
\hline Lot Area $\left(\mathrm{m}^{2}\right)$ & 5,161 & 7,469 & 5,367 & 5,623 & 2,250 & 3,129 & 3,129 & 32,128 & \\
\hline Residential GFA $\left(\mathrm{m}^{2}\right)$ & 31,325 & 31,325 & 24,312 & 35,895 & 20,356 & & & 143,213 & $71.6 \%$ \\
\hline Retail GFA $\left(\mathrm{m}^{2}\right)$ & 2,639 & 2,807 & 680 & 1,757 & 836 & 893 & 893 & 10,505 & $5.2 \%$ \\
\hline Commercial GFA $\left(\mathrm{m}^{2}\right)$ & & & & & & 20,019 & 20,019 & 40,038 & $20 \%$ \\
\hline $\begin{array}{l}\text { Other GFA }\left(\mathrm{m}^{2}\right) \\
\text { (institutional/ } \\
\text { Community) }\end{array}$ & & & 737 & 2,323 & & 1,657 & 1,657 & 6,374 & $3.2 \%$ \\
\hline 1 bedroom & 193 & 171 & 28 & 30 & 156 & & & 578 & $31.3 \%$ \\
\hline 2 bedrooms & 104 & 110 & 131 & 177 & 156 & & & 678 & $36.7 \%$ \\
\hline 3 bedrooms & 18 & 27 & 15 & 12 & 60 & & & 132 & $7.1 \%$ \\
\hline 4 bedrooms & & & & & 20 & & & 20 & $1.1 \%$ \\
\hline Parking (total) & 312 & 300 & 200 & 381 & 250 & 50 & 50 & 1,543 & \\
\hline Parking (residents) & 236 & 237 & 197 & 326 & 230 & & & 1,226 & $79.5 \%$ \\
\hline Parking (visitors) & & 5 & & 14 & 20 & & & 39 & $2.5 \%$ \\
\hline Parking (other) & & 58 & 3 & 41 & & & & 102 & $6.6 \%$ \\
\hline Parking (office) & 76 & & & & & 50 & 50 & 176 & $11.4 \%$ \\
\hline
\end{tabular}

Table 1 provides the attributes of the seven Bayside buildings, which define the input data required to synthesize the Bayside population and employment, as described in the next section. As shown in this table, a total of 1,855 residential apartment units are located in 6 of the 7 buildings. 440 (23.7\%) of these are Bachelor units, 578 (31.2\%) are 1-Bedrooms and the remainder have two or more bedrooms. $66.9 \%$ of the lot area is occupied by the 7 buildings, with residential units occupying $71.6 \%(143,213$ $\mathrm{m}^{2}$ ) of the buildings' gross floor area (GFA). The $56,916 \mathrm{~m}^{2}$ of nonresidential floorspace is primarily commercial ("office"), with an additional modest amount of retail, institutional/community floorspace. 1,543 parking spaces are provided in the precinct, with $79.5 \%$ (1,226 spaces) of these allocated to residential parking.

\section{Bayside population and employment synthesis}

\subsection{Introduction}

The key challenge in synthesizing population for Bayside development is establishing a statistical connection between the number of bedrooms in a Bayside residential unit and the attributes of the household and its individual household members (persons) that are likely to occupy this unit. This problem was complicated by various gaps and incompatibilities in the various base datasets available for supporting the population synthesis, as discussed in Section 6.2.

(Hammadi, 2020) provides a detailed review of the current state-of-the-art in population synthesis methods. He also discusses the technical issues in dealing with the Bayside synthesis issue. The final procedure developed for this task is summarized in Section 6.3, which also presents summary results of the application of this procedure. Section 6.4 concludes this section with a summary of the simple pro- 
cedure used to convert nonresidential floorspace into employment (jobs) by occupation type as required by GTAModel V4.1.

\subsection{Population synthesis data}

Two datasets are used to synthesize the Bayside population. The first is the 2016 Transportation Tomorrow Survey (TTS). TTS is a major one-day household travel survey conducted every five years in the extended Toronto region, the Greater Golden Horseshoe (GGH). The most recent survey was conducted in $2016.5 \%$ of GGH households, amounting to 162,000 households in total, were surveyed. For complete documentation of the 2016 TTS see (DMG, 2018). TTS is the basis for all travel demand modeling in the GGH, including the GTAModel. While the TTS gathers the most common household attributes, including number of persons, number of workers, number of vehicles, total household income and dwelling structure type, it does not collect information concerning the number of bedrooms in the household's dwelling unit - a key variable for TISP. Thus, additional information from other sources needs to be fused with TTS data in order to add this variable into the analysis.

The second dataset used in this study is Canadian Census data. A full census is conducted every five years, with the most recent one occurring in 2016. Among the information collected in the "long form" sub-sample of the census, both dwelling structure type and number of bedrooms are collected. Making use of this information in the TISP application, however, is not straightforward, primarily because Statistics Canada only releases a Public Use Microdata File (PUMF) at the Census Metropolitan Area (CMA) level - the equivalent of the SMSA in the US (Statistics Canada, 2019). In virtually all population synthesis procedures, the disaggregated PUMF data are used to construct a sample joint distribution across the control variables of interest in the synthesis. This can be done with the Canadian PUMF, but the very large geographic area over which the PUMF records are drawn raises questions concerning its representativeness for synthesizing households (and associated persons) for a central area precinct such as Bayside.

\subsection{Population synthesis procedure}

As discussed in sub-section 6.2, two datasets are used for population synthesis; that is, PUMF and TTS. Each dataset deals with different levels of geography. PUMF data deals mainly with the CMA while TTS data can be customized to smaller geographic areas; for example, a planning district (PD) or a traffic analysis zone (TAZ). Table 2 shows the control variables used in the population synthesis for Bayside precinct. The number of bedrooms (No. BR) variable represents the relevant development physical characteristic in the population synthesis process. 
Table 2. Control variables of population synthesis for Bayside development

\begin{tabular}{|l|l|l|l|}
\hline \multicolumn{2}{|c|}{ Household Set } & \multicolumn{2}{c|}{ Person Set } \\
\hline Attribute & Category & Attribute & Category \\
\hline No. BR & $0,1,2,3,4$ & No. BR & $0,1,2,3,4$ \\
HH_Size & $1,2,3,4+$ Persons & Sex & F - Female, M - Male \\
Income Class & $1-\$ 0$ to $\$ 14,999$ & Age & $0-70+$ \\
& $2-\$ 15,000$ to $\$ 39,999$ & Occupation & G - General Office / Clerical \\
& 3- $\$ 40,000$ to $\$ 59,999$ & & M - Manufacturing / Construction / Trades \\
& $4-\$ 60,000$ to $\$ 99,999$ & & P - Professional / Management / Technical \\
& $5-\$ 100,000$ to $\$ 124,999$ & & S - Retail Sales and Service \\
& $6-\$ 125,000$ and above & & O- Not Employed \\
& & Employment Status & F- Full Time \\
& & & H - Work at home full time \\
& & & J - Work at home part time \\
& & & O - Not employed \\
& & & P - Part time \\
& & & 9 - Unknown \\
\hline
\end{tabular}

The No. BR control variable is available in PUMF data but not in TTS data. This makes the population synthesis not conventional in the sense of fitting a sample data to the marginal totals of the area. The population synthesis procedure for Bayside precinct mainly performs two tasks: fuses the No. BR variable from PUMF data into TTS data and traces (cascades) the data between the levels of geography for the "apartment" category of dwellings. Figure 10 shows the population synthesis approach of data cascading of Household and Person sets for the Bayside precinct. In the first stage the tabulation of the three household control variables of PUMF data in the Toronto CMA geography area is fitted (proportioned) to the marginals of the two household control variables of the TTS data in the planning district one (PD1) area, for each No. BR category.

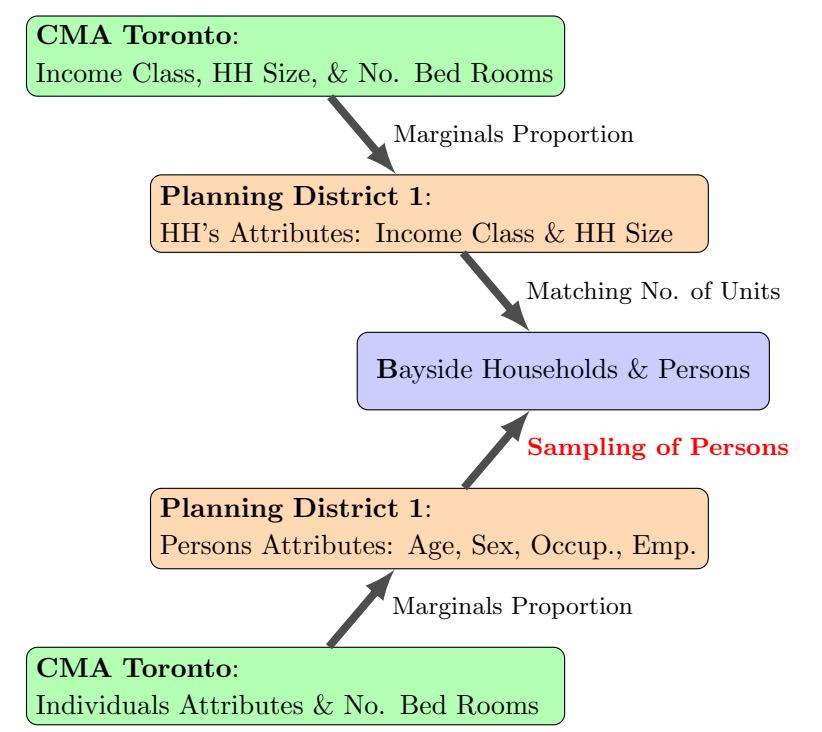

Figure 10. Cascading data for Household and Person sets of Bayside development 
The generated household tabulation, with the three control variables, at the PD1 geography is matched to the number of dwellings in Bayside precinct, for each No. of BR category. Each dwelling in Bayside precinct is occupied by one probable household. Figure 11 shows the distribution of the synthesized Household set for the Bayside precinct by the three control variables shown in Table 2. ${ }^{22}$ The first stage of generating the Person's set forms the individuals' tabulation, for all the household and person control variables as in Table 2, at the Toronto CMA geography area. This step integrates the attributes of persons with their respective households' attributes to ensure consistency between the two sets. The CMA tabulation is fitted (cascaded) to the respective PD1 marginal totals of the same control variables by proportioning the counts of individuals with similar attributes in the CMA and PD1 geographic areas respectively. This results in an individuals' tabulation with the variable of No. BR included (which is not available in TTS data) at the PD1 geographic area.

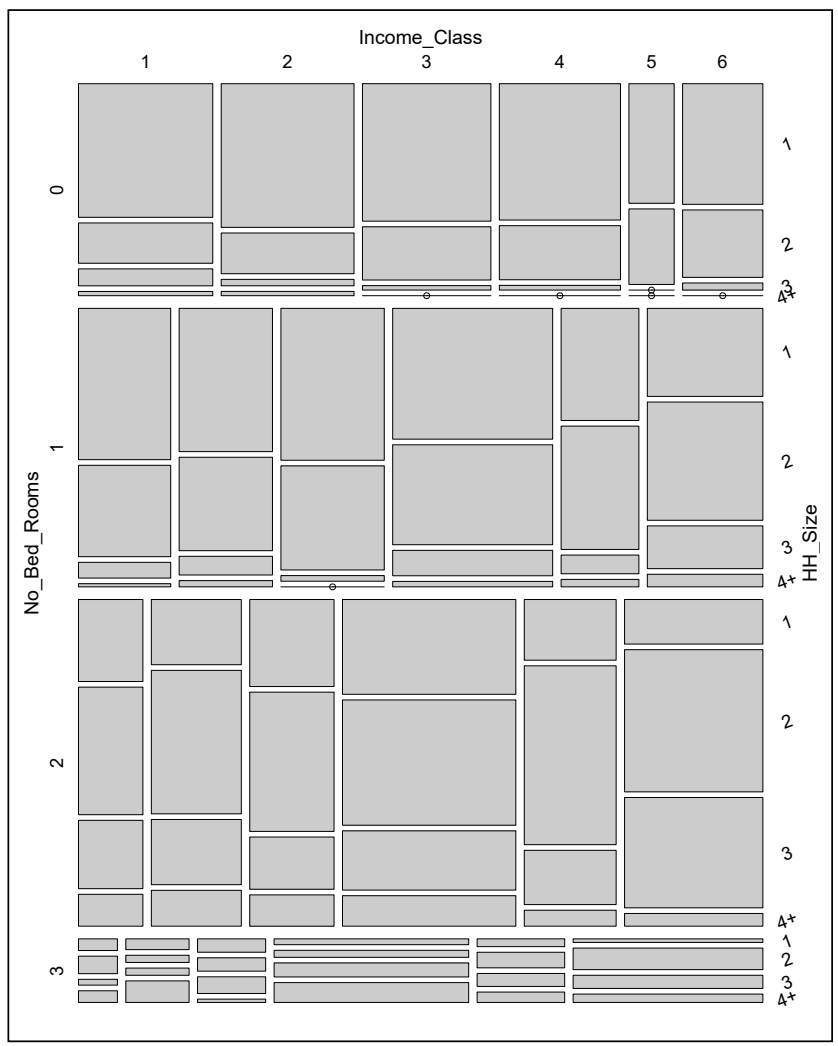

Figure 11. Distribution of the synthesised Household set for the Bayside development by the control variables

However, the individual's tabulation cannot be matched to the dwellings or the Household set of Bayside directly as done in the generation of the Household set for Bayside precinct. The probability space of the joint distribution of individuals' and households' attributes; that is, with the seven control variables and their respective categories, is much larger than the joint distribution space of the Household attributes with three control variables as shown in Figure 11. Sampling technique is used to select persons for each category of the Household Size and dwelling type by No. BR variables in the Household set as shown in Figure 12. Each column in the figure represents the choice set of the respective

\footnotetext{
${ }^{22}$ This is a mosaic plot where the rectangles' sizes are equivalent to the proportions of the variable's joint distribution. No. BR category of $4 \mathrm{BR}$ is not shown in the figure because it represents only $1 \%$ of the total number of units as shown in Table 1.
} 
control header variables. The probability distribution of each choice set is calculated from the respective CDF of the individuals tabulation in the PD1 area. Both households and persons, in the Household and Person sets, are uniquely indexed and sub-indexed respectively to maintain the relationship between each household and its individuals.

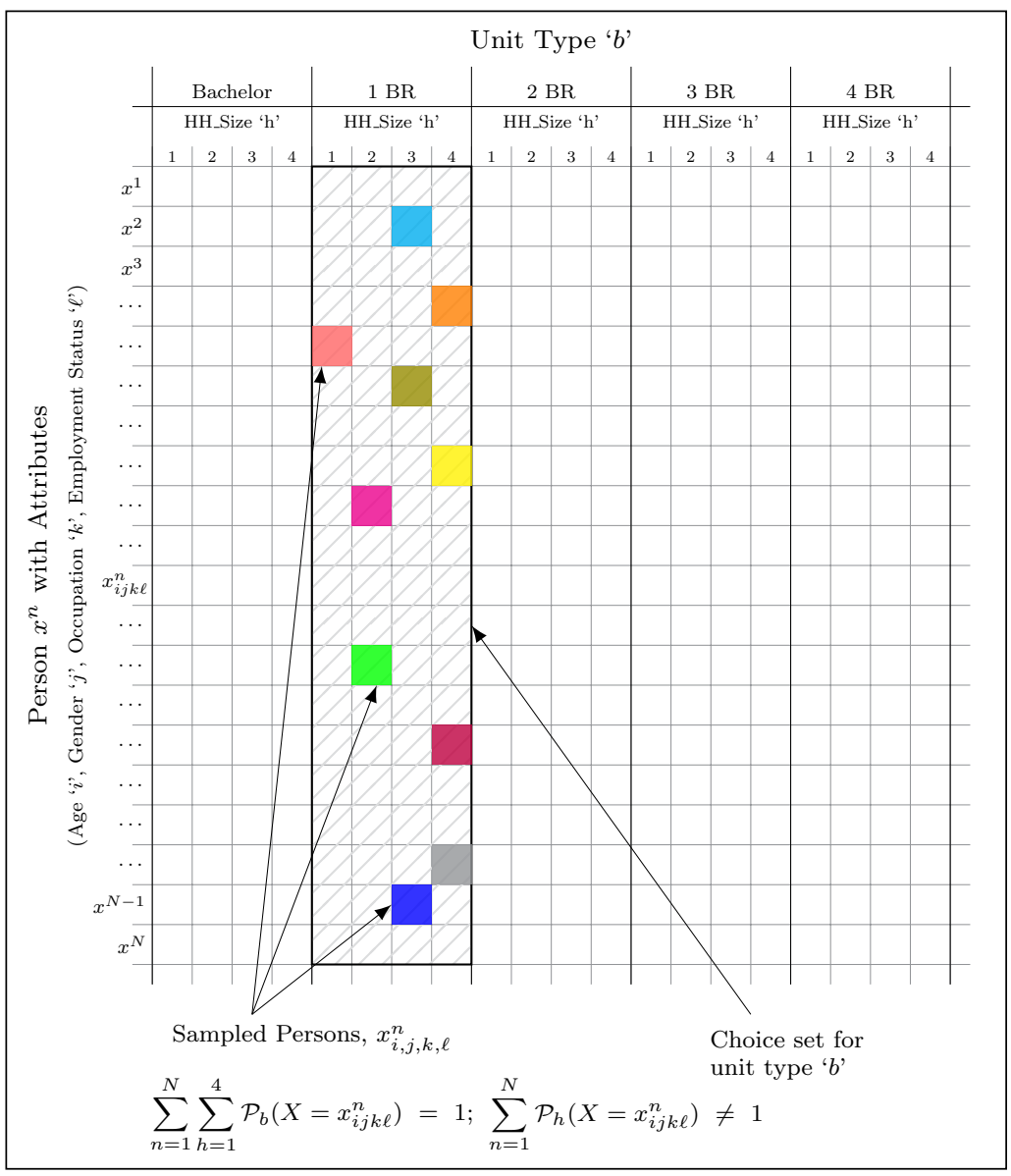

Figure 12. Sampling of persons for each dwelling type based on household size

\subsection{Job synthesis procedure}

While many factors can affect the amount of floorspace that a worker on average occupies, a standard rule of thumb in the City of Toronto is to assume an average floorspace-per-worker ratio of $25 \mathrm{~m}^{2}$ per employee (WSP, 2018). This ratio is used in this study to generate the number of workers assumed to be employed in the nonresidential floorspace of Bayside buildings.

GTAModel requires employment to be categorized by four occupation groups and by full- $(\mathrm{F})$ and part-time (P) employment status. The four occupation groups are the TTS occupation categories: Professional, Managerial or Technical (P); General Office (G); Sales and Services (S); and Manufacturing, Construction or Trades (M). It is assumed that Retail floorspace employment is $100 \%$ Sales. For Commercial and "Other" nonresidential floorspace, it is assumed that the employment is distributed among the other three occupation groups based on the 2016 TTS occupation distribution for PD1. The full or part-time split of workers in each occupation group is also based on the PD1 splits observed in the 2016 TTS. Applying these assumptions to the Bayside development yields the district's employment by occupation and employment status shown in Table 3. 
Table 3. Bayside development employment by occupation and employment status

\begin{tabular}{|c|c|c|c|c|c|c|c|c|}
\hline Non-Residential Floor Space & \multicolumn{6}{|c|}{ Commercial + Other (Institutional / Community) } & \multicolumn{2}{|c|}{ Retail } \\
\hline Gross Floor Area (GFA) $\left(\mathrm{m}^{2}\right)$ & 43,352 & & & & & & 10,505 & \\
\hline Employment Rate (Employee $/ \mathrm{m}^{2}$ ) & 0.04 & & & & & & 0.04 & \\
\hline Occupation & $\mathrm{P}$ & $\mathrm{P}$ & M & M & G & G & $\mathrm{S}$ & $\mathrm{S}$ \\
\hline Employment Status & $\mathrm{F}$ & $\mathrm{P}$ & $\mathrm{F}$ & $\mathrm{P}$ & $\mathrm{F}$ & $P$ & $\mathrm{~F}$ & $\mathrm{P}$ \\
\hline Percentages in TTS PD1 Data set & $74.06 \%$ & $4.21 \%$ & $2.34 \%$ & $0.18 \%$ & $16.77 \%$ & $1.74 \%$ & $71.10 \%$ & $28.90 \%$ \\
\hline Number of Employees & 1,284 & 73 & 41 & 3 & 291 & 30 & 299 & 121 \\
\hline Total Employment & & & & & & 1,722 & & 420 \\
\hline
\end{tabular}

\subsection{Verification and validation of population and employment synthesis results}

One of the conventional statistics used in measuring the goodness of fitting (synthesizing) population contingency table (cross tabulation) from a sample contingency table and control variables' marginals (totals) is the odds ratio which is based on the probabilities' likelihood of cells counts (frequencies) in the sample and population tabulations respectively. The iterative proportional fitting (IPF) process maintains the same odds ratios between the sample and population tables. However, the population synthesis process used for fitting disaggregate population (households and persons) for Bayside development, as discussed in Section 6.3 and illustrated in Figure 10, is based on marginals proportion between CMA and PD1 levels of geography in the first stage and then on matching of households to number of units and sampling of persons (as shown in Figure 12) in the second stage. Thus, the odds ratio statistic cannot be used because the implemented approach for Bayside development is different than fitting a population from a sample since there is no sample of the likely households or persons who will occupy the Bayside development units upon the project's completion. 
Another statistic for measuring the goodness-of-fit of the synthesized population is the chi-square $\left(\chi^{2}\right)$ statistic, which is also based on the likelihood between the observed and estimated (expected) frequencies of the cross tabulations. Since there are no observed (actual) values of any of the cross tabulation cells for the attributes of the likely population that will occupy Bayside development upon completion this $\left(\chi^{2}\right)$ statistic cannot be used. However, the proportion and match population synthesis procedure used in this prototype implementation of TISP model produced a plausible distribution of the likely households' attributes for Bayside development, as depicted in the mosaic plot in Figure 11. The employment synthesis procedure, as discussed in Section 6.4, is based on the rule of thumb average floorspace-perworker ratio of $25 \mathrm{~m}^{2}$ per employee. This practice of estimating employment for non-residential floor space based on FSW ratio is widely used by consultants and the City. Distribution of the likely Bayside employment (list of jobs) among the different occupation and employment status categories, as shown in Table 3, is based on the percentages of these categories in PD1 in TTS dataset.

Validating the synthesized Household, Persons, and Employment sets for Bayside development, as discussed in Sections 6.3 and 6.4 respectively, is not possible because the observed (ground truth) of households and persons attributes' totals of the likely residents/occupants of Bayside development are not known before the project's construction completion and occupation of its units. Therefore, a validation exercise for Bayside development synthesized population was not pursued. However, the total number of dwellings, by their type (number of bedrooms), in Bayside development are known from the development architectural characteristics, as shown in Table 1. These totals are maintained as constraints throughout the synthesizing process of Household set as discussed in Section 6.3.

\section{$7 \quad$ Bayside development case study results}

Table 4 summarizes the number of trips by Bayside residents generated by GTAModel, categorized by the number of bedrooms of the households' dwelling units. In total, 3,424 persons within 1,848 households generated a total of 7,230 daily weekday trips, yielding average household and person daily trip rates of 3.91 and 2.11 trips per day, respectively. Household daily trip rates are seen to increase virtually linearly with dwelling unit size (and, implicitly household size), while person daily trip rates are essentially invariant across dwelling unit size. These average trip rates are typical of PD1 trip rates observed in TTS. They tend to be a bit low relative to rates sometime observed elsewhere, since TTS is known to undercount non-work or school-related walk trips. While this is unfortunate for modeling travel within a dense core area such as Bayside, this not something that can be corrected within the current study.

Figure 13 displays mosaic plots of Bayside residents' number of household daily trips by: income class and household size (Figure 13.a), number of bedrooms and household size (Figure 13.c) and number of bedrooms and income class (Figure 13.d). The Bayside distribution of household trips by income and household size (Figure 13.a) is also compared to the distribution of PDI trips observed in the 2016 TTS (Figure 13.b). From this latter comparison it is seen that, while the Bayside population has been generated using PD1 data, the specifics of the Bayside development result in an income-household size 
distribution that differs from the overall PD1 distribution in several ways, and, hence, the overall trip distribution also varies accordingly. This is further illustrated in Figure 14, which plots the daily household trip rates for all 64 developed traffic analysis zones (TAZ) in PD1 along with the Bayside average trip rate. The Bayside average trip rate of 3.91 is consistent with the PD1 trip rates, lying within the 1 standard deviation band of values, but it is higher than the PD1 average of 3.44 trips per day.

Table 4. Bayside development residents' weekday trips by number of bedrooms

\begin{tabular}{|l|rrrrrr|}
\cline { 2 - 7 } \multicolumn{1}{c|}{} & 0-BR & 1-BR & 2-BR & 3-BR & 4-BR & Total \\
\hline Trips (GTAMode 1) & 1259 & 2111 & 3057 & 678 & 125 & 7230 \\
Total HH's & 440 & 578 & 678 & 132 & 20 & 1848 \\
HH's with trips & 369 & 518 & 626 & 123 & 20 & 1656 \\
HH's with 0 trips & 71 & 60 & 52 & 9 & & 192 \\
Total Persons & 602 & 946 & 1463 & 354 & 59 & 3424 \\
Persons with Trips & 521 & 877 & 1382 & 339 & 59 & 3178 \\
Persons with 0 Trips & 81 & 69 & 81 & 15 & & 246 \\
HH Trip Rate $^{\dagger}$ & 2.9 & 3.7 & 4.5 & 5.1 & 6.3 & $\mathbf{3 . 9 1}$ \\
Person Trip Rate $^{\dagger}$ & 2.1 & 2.2 & 2.1 & 1.9 & 2.1 & 2.11 \\
\hline
\end{tabular}

${ }^{\dagger}$ Based on total number of households / persons. 

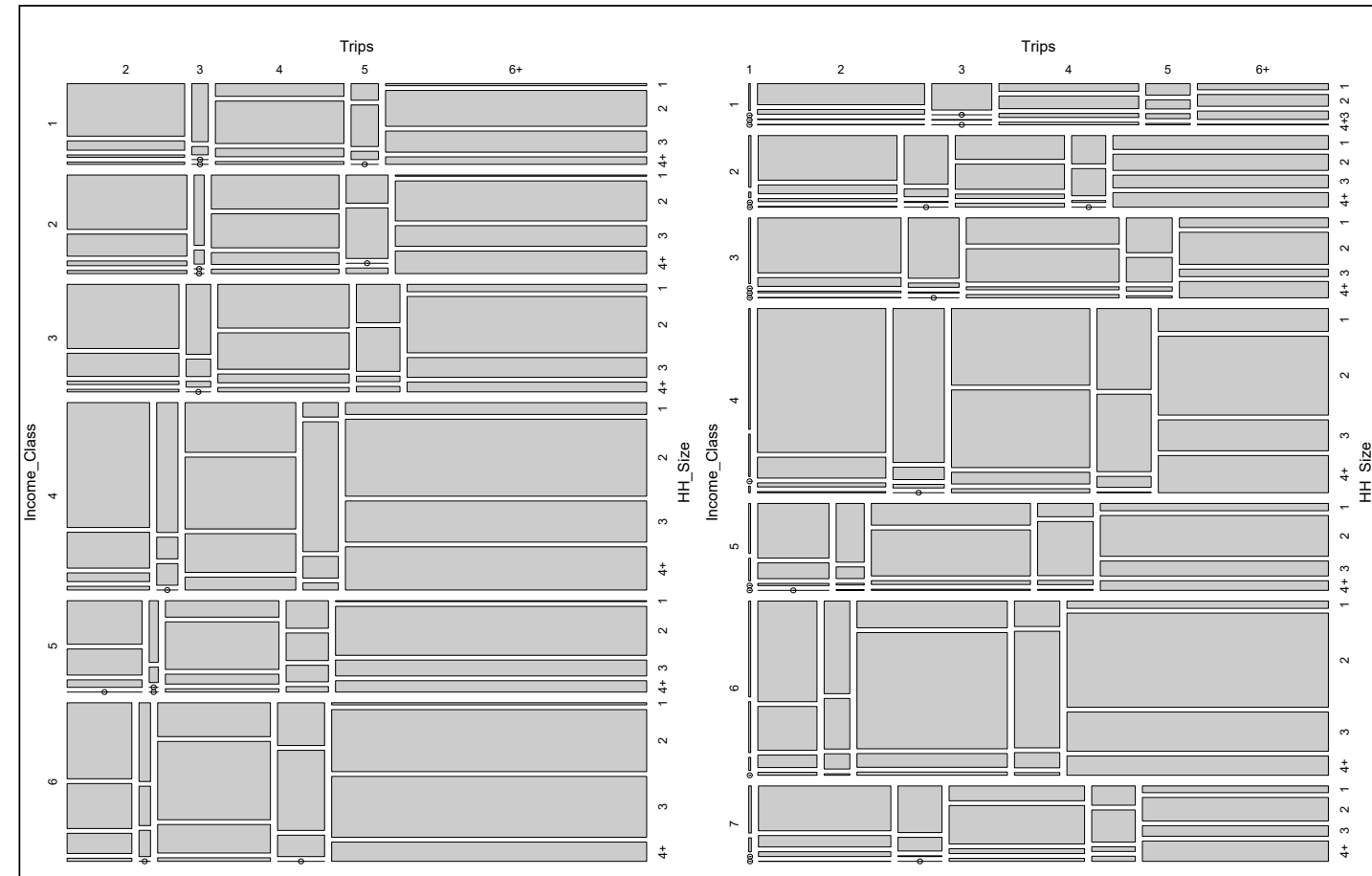

(a) Bayside Trips, Income Class, and HH_Size

(b) PD1 Trips, Income Class, and HH_Size
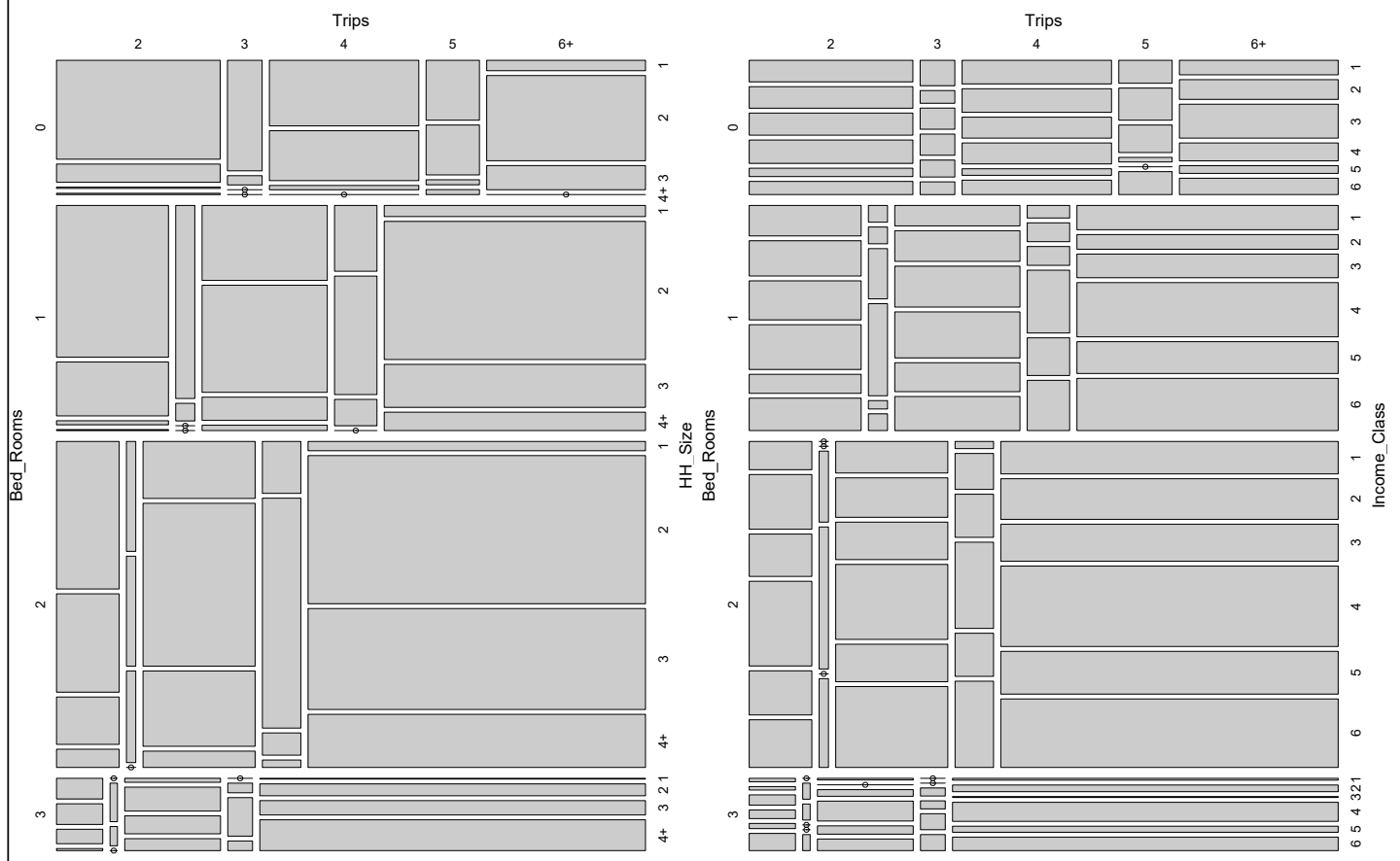

(c) Bayside Trips, No_Bed Rooms, and HH_Size

(d) Bayside Trips, No_Bed Rooms, and Income Class

Figure 13. Trips by number of bedrooms, income class, and household size for Bayside development and planning district 1 


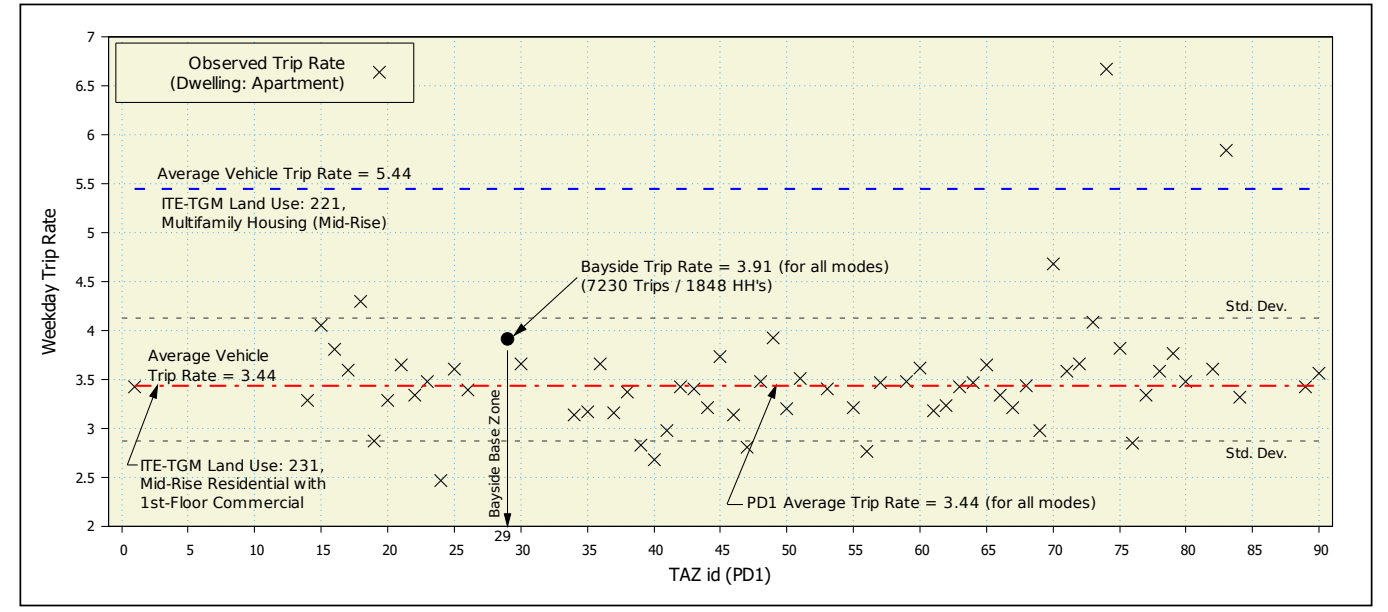

Figure 14. Observed household trip rates in Planning District 1 developed TAZ zones and estimated Bayside development average trip rate, versus ITE Trip Generation Manual trip generation rates

The relevant auto trip rates of the Institute of Transportation Engineers (ITE) Trip Generation Manual (TGM) are also shown in the figure. The TGM auto trip rates depend on the selected land-use category and the trip rates for the two most relevant land-uses; that is, land-use 231 (Mid-Rise Residential with $1^{\text {st }}$-floor commercial) ${ }^{23}$ and land-use 221 (Multifamily Mid-Rise Housing) are traced on the figure with horizontal lines. Deciding on a separate TGM auto trip rate for each TAZ zone (of the 64 developed zones in PD1) requires identifying the actual land-use category in each TAZ zone and matching it to one of the designated land-uses in the ITE-TGM. This is not an objective for the current study. Note that the TGM rates are vehicle trips only, whereas the TISP/GTAModel and TTS estimated and observed rates respectively are for all commute modes.

The wide range in travel (in contrast to traffic) related impacts of the new development that can be estimated from the TISP model (using an ABM model system like GTAModel) are much more detailed (spatiotemporal distribution of the trips, residents and non-residents trips origins and destinations, commute mode shares, etc.) than the conventional (non-behavioral) methods for estimating the traffic (auto) impacts on the local road network at the boundary of the development. A comparison of Bayside residents' weekday and AM/PM peak hour home-based auto trips using the three methods of TISP (ABM), ITE-TGM trip rates for land-use 231, and the project's prior traffic impact study auto trip

\footnotetext{
${ }^{23}$ It should be noted that the weekday vehicle trip rate (per dwelling unit) for land-use 231 (3.44), for a site setting/location of general urban/suburban, is based on one observed rate as shown on page 272 of the manual (ITE, Trip Generation Manual, 2017).
} 
rates are further explored in Table 5.

Table 5. Bayside residents' weekday and AM/PM home-based auto trips as estimated by GTAModel versus the ITE TGM and the project traffic impact study estimated trips

\begin{tabular}{|c|c|c|c|c|}
\hline & \multirow{5}{*}{$\begin{array}{l}\text { GTAModel } \\
\text { Model Run } \\
\text { (V. 4.1) }\end{array}$} & \multirow{3}{*}{\multicolumn{2}{|c|}{$\begin{array}{c}\text { ITE's TGM } \\
\text { (Land-Use 231) }\end{array}$}} & \multirow{5}{*}{$\begin{array}{l}\text { TIS (2011 } \\
\text { BA Group } \\
\text { Survey) }\end{array}$} \\
\hline & & & & \\
\hline & & & & \\
\hline & & \multirow[t]{2}{*}{ Generator } & Adjacent Street & \\
\hline & & & Traffic & \\
\hline Total Auto Trips & 1484 & $1460(-1.6 \%)$ & $1460(-1.6 \%)$ & \\
\hline AM Peak Hour Auto Trips & 131 & $103(-21 \%)$ & $69(-47 \%)$ & $84(-36 \%)$ \\
\hline PM Peak Hour Auto Trips & 103 & $69(-33 \%)$ & $126(+22 \%)$ & $82(-20 \%)$ \\
\hline
\end{tabular}

The total and AM/PM peak hour auto trips shown in the table, by each method, are estimated based on totally different notions of vehicular trips estimation. The TISP/GTAModel likely auto trips generated by Bayside residents are estimated using an ABM model for a typical weekday residents' activities (as shown in the activities class diagram in Figure 6), their commute modes shares (as shown in Figure 17a), and their 24-hours trips distribution (as shown in Figure 15). However, the ITE-TGM vehicle trips estimates are based on transfer of residential auto trip generation rates and regression relationships between different geographical areas, as discussed in Section 2.2. The prior TIS auto trips (by BA Group), are based on the observed (surveyed) auto trip rates of similar occupied developments' sites to Bayside development. The comparison of auto trips in Table 5 is not intended to validate the TISP/ GTAModel auto trips estimations, as the GTAModel is a well calibrated and validated travel demand forecasting model and in operational use by many transportation agencies across the Toronto GTA region, as discussed in Section 4.1. ${ }^{24}$

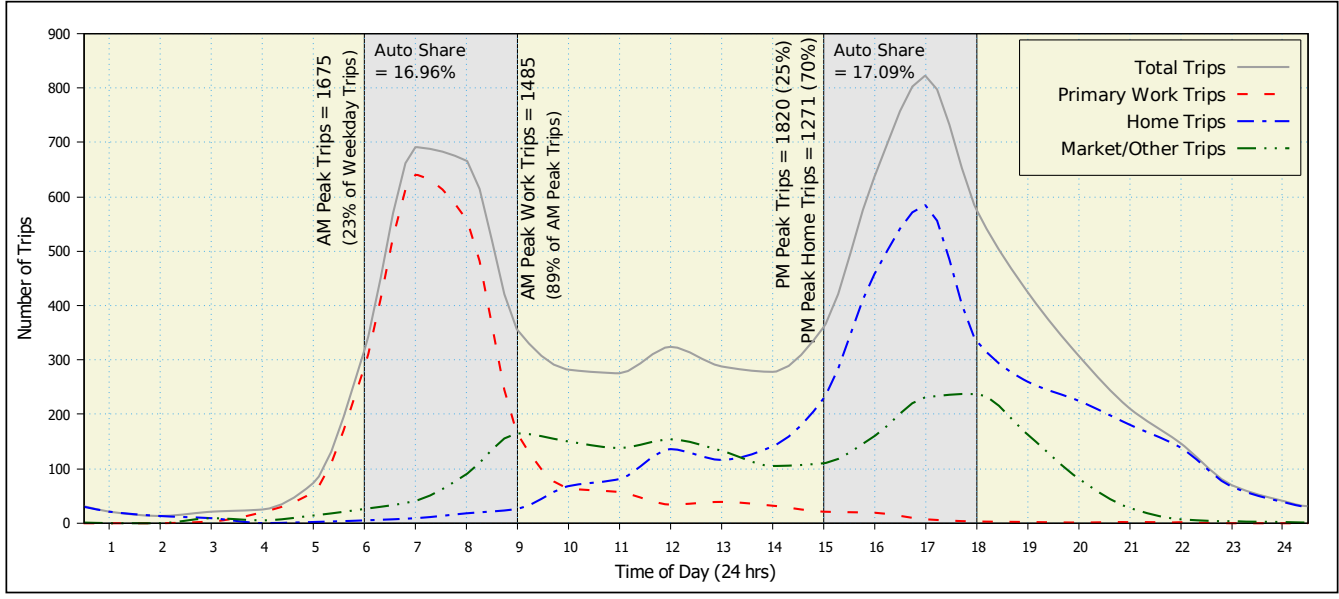

Figure 15. Temporal distribution of Bayside development residents' trips by purpose

In terms of the ground truth of the AM/PM peak hour auto trips, the observed (surveyed) auto

\footnotetext{
${ }^{24}$ The close match between the total auto trips estimates by ITE-TGM and TISP/GTAModel (1.6\% difference only) is most probably a coincidence as the notion of estimation in each approach is totally different as discussed above.
} 
trip rates of similar completed, occupied developments sites, and close enough to Bayside development could be credible estimates for the traffic impact, by the new and existing vehicular trips, on the boundary road network of the development. However, this traffic impact is far from estimating the full range of all the travel related impacts of the new development, using an ABM model system as GTAModel, which include, in addition to auto trip estimates, the shares of other commute modes and the spatiotemporal distribution of the trips by residents and non-residents of the development. The development and implementation of the prototype TISP model for Bayside development, demonstrates the feasibility and advantages of using more advanced and sophisticated travel demand forecasting model system (as GTAModel V4.1 model) in estimating the travel behavior of residents and non-residents of a major land development.

Figure 15 plots the temporal distribution of Bayside residents' trips by purpose. It displays the expected diurnal peaking, with most trips to work occurring during the morning peak period and most return-home trips occurring in the afternoon peak and evening time periods. As marked on the figure, the AM and PM peak trips represent $23 \%$ and $25 \%$ respectively of the total weekday trips generated by Bayside synthesized households and persons. 89\% of the AM peak trips are home-based-work (HBW) trips and this phenomenon of the dominance of the HBW trips is evident in the travel demand forecasting literature. ${ }^{25}$ The auto mode share in the AM/PM peak period trips is around $17 \%$ only and this is attributed to the feasibility of using other commute modes for HBW trips, especially 'transit' and 'walk' as illustrated in Figure 17(a). This scheme of low auto dependence in HBW trips is mostly applicable in the context of downtown urban area, where the intensity of dwellings per unit of land (in terms of buildings heights) and jobs increase closer to the city's central business district (CBD) and transit services are more available. This could also be attributed to the less availability of cheap parking facilities in the downtown area which makes using the auto mode for downtown destinations trips not feasible.

Table 6 tabulates Bayside residents' trips by destination activity type. This distribution is typical of Toronto residents' weekday activity patterns, with "primary work" being the largest non-home activity destination, accounting for $28 \%$ of trips, and "return-home" accounting for $44 \%$ of trips (reflecting the existence of complex $2+$ non-home activity chains).

Table 6. Bayside development residents' trips by destination activity type

\begin{tabular}{|l|rr|}
\hline Destination & No. of Trips \\
\hline Home & 3,193 & $44.2 \%$ \\
Primary Work & 2,012 & $27.8 \%$ \\
Individual Other & 1,006 & $13.9 \%$ \\
Market & 626 & $8.7 \%$ \\
Work Based Business & 193 & $2.7 \%$ \\
Joint Other & 94 & $1.3 \%$ \\
Joint Market & 53 & $0.7 \%$ \\
Secondary Work & 53 & $0.7 \%$ \\
\hline Total Trips & 7,230 & \\
\hline
\end{tabular}

\footnotetext{
${ }^{25}$ It is not that $100 \%$ of the synthesized workers are loaded to the transport network, in the activities and trips generation simulation, because not every worker goes to work every day; some might be on sick leave, on vacation, etc.
} 
Figure 16 plots Bayside residents' trip destinations for all trip purposes (Figure 16.a) and home-towork trips (Figure 16.b). In both cases PD1 locations outside of Bayside are the dominant destination choice. Bayside is the second largest destination for total trips, largely for non-work trips, given that only $2.2 \%$ of residents stay within the precinct for their place of work. Very few trips are made to locations outside the City of Toronto ( $2.4 \%$ in total; $4.2 \%$ for work). In general, Bayside residents' trip-making is very locally focused with $73.3 \%$ of work trips and $83.5 \%$ of total trips being destined to either Bayside itself or the rest of PD1. Such estimation and illustration of Bayside residents' trips destinations would not be possible without synthesizing Household and Person sets to the development dwellings, as discussed in Section 6, to enable the using of an ABM model system (like GTAModel model) for generating the rule-based weekday activities and their associated travel behavior.

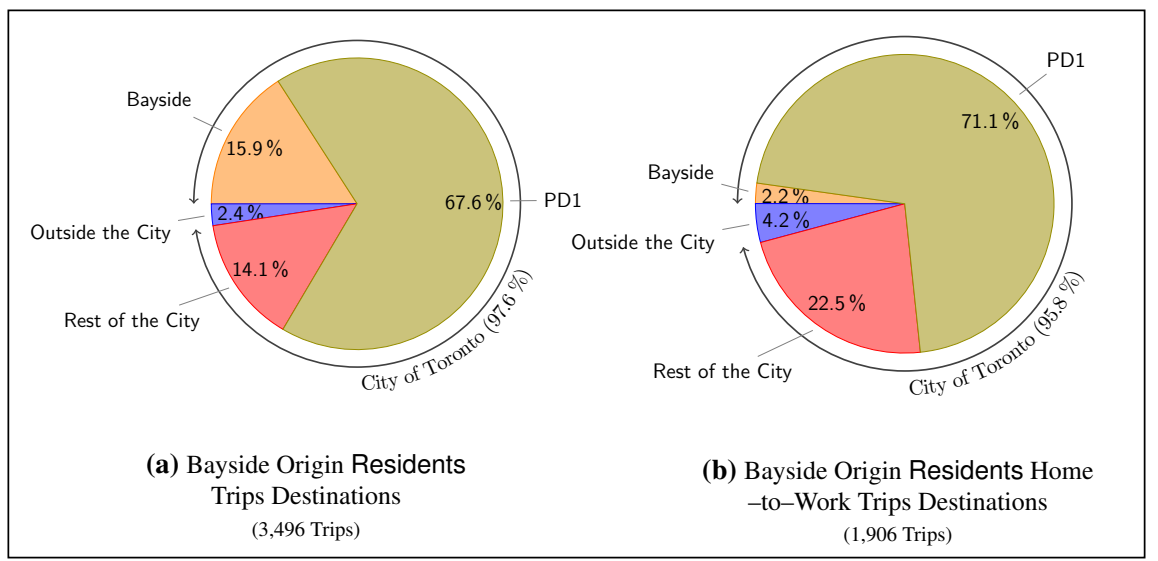

Figure 16. Destinations of trips originating in Bayside development by residents

This localized trip-making is further seen in Figure 17.a, which plots overall daily mode choices, for all trip purposes, for Bayside residents. Walk is the number one travel mode, accounting for $32.3 \%$ of all trips, with transit being second with $30.7 \%$ of trips. A significant bicycle mode share of $8.1 \%$ is also observed. Thus, in total, $71.1 \%$ of Bayside resident's trips are made by a non-auto-based mode. These numbers can be compared to the daily, all-purpose mode shares for City of Toronto residents as a whole (Figure 17.b), in which walk, transit and bicycle mode shares, while still comprising a total of $44.5 \%$ of trips (which is quite decent by North American standards), are much less than for Bayside residents, and in which auto-based modes comprise the remaining $55.5 \%$ of trips.

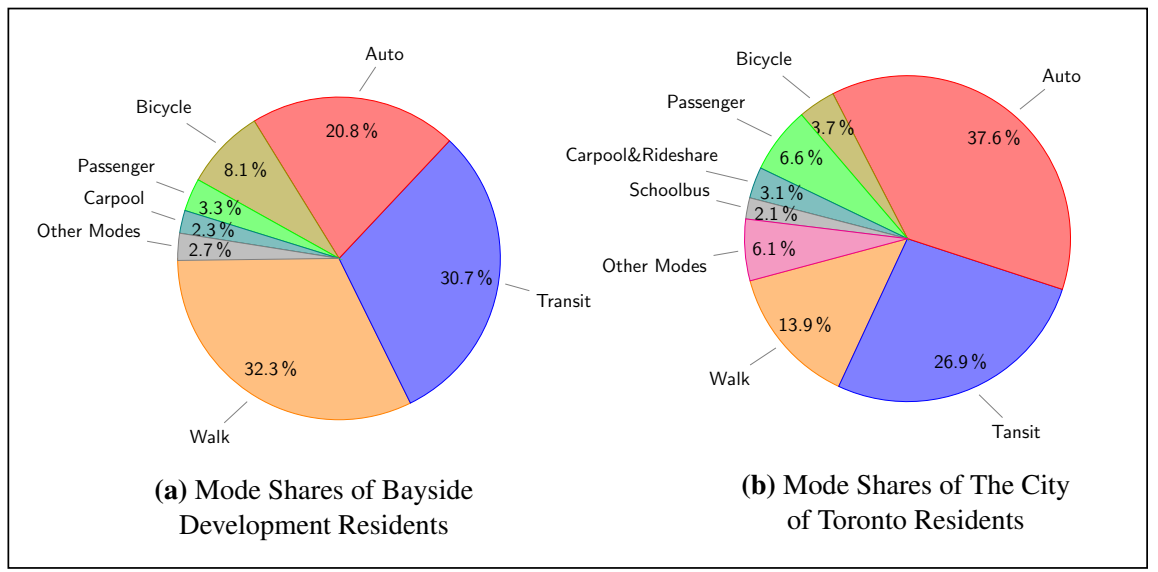


Figure 17. Destinations of trips originating in Bayside development by residents

GTAModel also endogenously generates the driver's license possession (yes/no) for all persons 16 years of age or older and household auto ownership levels as a function of socio-economic, spatial and transportation accessibility variables (household vehicle ownership is also a function of the number of drivers in the household). Table 7 shows the resulting distribution of number of households by number of vehicles generated by GTAModel for Bayside households. As indicated by this table, a majority of Bayside residents (56.7\%) are projected to not own a vehicle, and less than $10 \%$ own two or more vehicles.

It is interesting to note that GTAModel predicts that Bayside residents will own or lease 996 vehicles. As shown in Table 7, however, 1,226 residents' parking spaces are included in the precinct design. Presumably this amount could be reduced considerably, thereby saving building construction and operating costs and/or freeing up space within the buildings for other purposes.

Table 7. Bayside development households' vehicle ownership

\begin{tabular}{|l|rrrrrr|}
\cline { 2 - 7 } \multicolumn{1}{c|}{} & 0-Veh. & 1-Veh. & 2-Veh. & 3-Veh. & 4-Veh. & Total \\
\hline Number of Households & 1,048 & 627 & 145 & 25 & 1 & 1,848 \\
Percentage of Households & $56.7 \%$ & $33.9 \%$ & $7.8 \%$ & $1.4 \%$ & $0.05 \%$ & \\
Number of Vehicles & 0 & 627 & 290 & 75 & 4 & 996 \\
\hline
\end{tabular}

Turning to non-resident travel to or from Bayside, a total of 4,210 daily trips are made by nonresidents to or from or within Bayside. This represents $36.8 \%$ of the total Bayside-based daily trips of 11,440 (7,230 and 4,210 trips by resident and non-residents respectively). Figure 18 and Table 8 present the distribution of non-resident trips origins for trips destined to Bayside. While $35.5 \%$ of these trips originate in either PD1 or Bayside itself, clearly non-resident travel to Bayside is not nearly as localized as Bayside residents' travel is (as shown in Figure 16). As seen in Figure 18, 42.9\% of the non-residents' trips to Bayside are coming from the City of Toronto outside of the downtown PD1 area and $21.7 \%$ are coming from outside the City altogether.

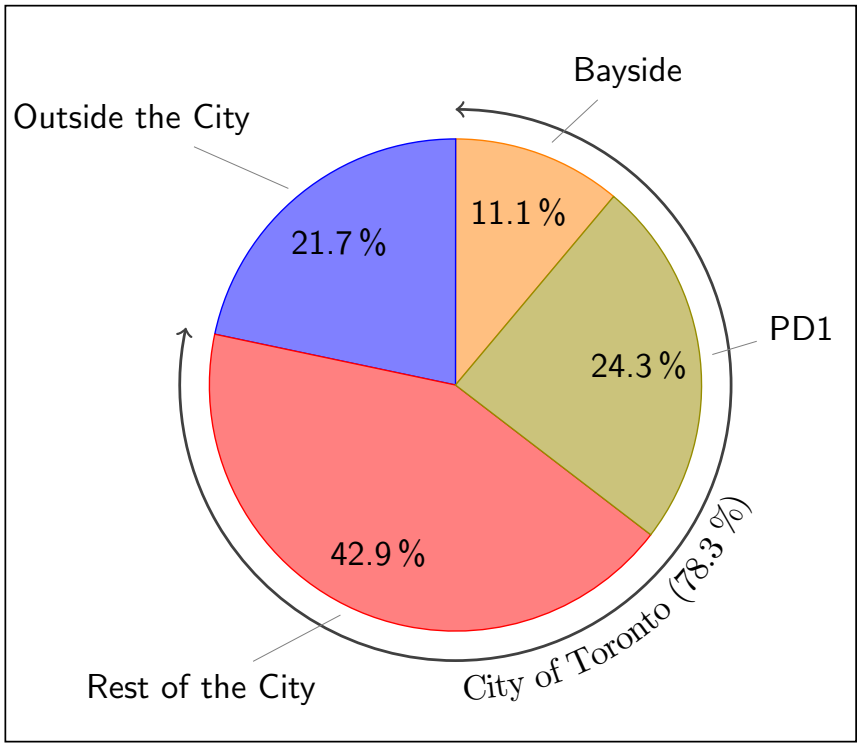

Figure 18. Spatial origins of non-residents' trips to Bayside 
Table 8. Non-residents' trips to/from Bayside development

\begin{tabular}{|l|rrr|}
\cline { 2 - 4 } \multicolumn{1}{c|}{} & \multicolumn{3}{c|}{ Trips } \\
\hline Geography & $\begin{array}{l}\text { Destination } \\
\text { Bayside }\end{array}$ & $\begin{array}{l}\text { Origin } \\
\text { Bayside }\end{array}$ & Total \\
\hline Bayside & 233 & 235 & 468 \\
PD1 & 506 & 518 & 1,024 \\
Rest of the City & 891 & 915 & 1,806 \\
Outside the city & 475 & 437 & 912 \\
\hline Total & 2,105 & 2,105 & 4,210 \\
\hline
\end{tabular}

Non-residents' trips to Bayside by trip purpose also differ from that by Bayside residents. Table 9 and Figure 19 breaks down these trips by trip purpose. As seen in this figure, $86 \%$ of the non-residents' trips to Bayside are work related trips. This is not surprising considering that Bayside precinct has two commercial buildings and $56,917 \mathrm{~m}^{2} \mathrm{GFA}(28.4 \%$ of the total precinct GFA) of commercial, retail and institutional floor space as shown in Table 1.

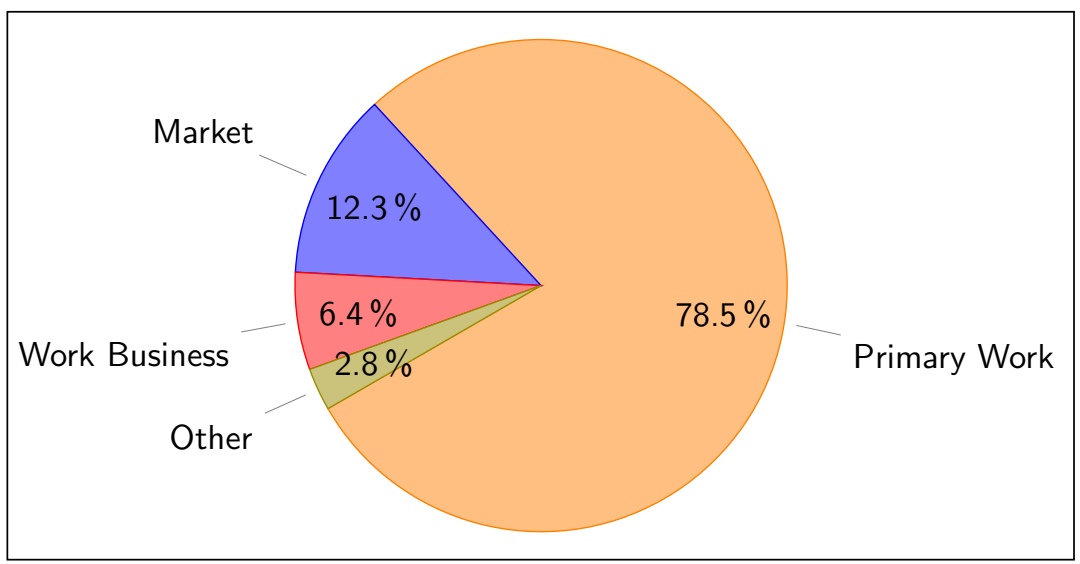

Figure 19. Non-residents' trips to Bayside by trip purpose

Table 9. Non-residents' trips to Bayside development by trip purpose

\begin{tabular}{|l|r|}
\hline Trip Purpose & Number of Trips \\
\hline Primary Work & 1,652 \\
Market & 259 \\
Work Business & 135 \\
Secondary Work & 32 \\
Joint Market & 27 \\
\hline Total & 2,105 \\
\hline
\end{tabular}




\section{$8 \quad$ Summary and future work}

This paper presents a prototype sketch planning procedure for assessing the likely transportation impacts of a new development site. It explores the use of an advanced agent-based microsimulation (ABM) regional activity-travel demand model system for this purpose. In the case study examined in the paper, the Bayside Phase 2 precinct in the Toronto waterfront district, it is found that the GTAModel V4.1 ABM activity-travel demand forecasting model system can, indeed be used in this task. It generates very detailed estimates of both resident and non-resident travel to, from and within the precinct. To the extent that was possible to do, these results were found to be comparable to ITE Trip Generation Model results for the precinct. The TISP results, however, are far more detailed and useful for precinct design and other planning purposes than the simple TGM vehicle trip predictions.

This use of GTAModel for sketch planning purposes is only possible due to its very short model system run times that permit rapid (but not yet "real-time") assessments of alternative precinct architectural designs. Most activity- and trip-based travel demand model systems are not able to match this computational performance and so are generally unsuitable to this task. This example emphasizes the need for such model systems to compute much quicker, so that they are more useful, not just for possible sketch planning purposes, but a wide range of planning applications in general (Miller, 2020).

This paper also extends existing population synthesis methods to permit a direct translation of a precinct physical design (expressed in terms of number of residential units by number of bedrooms per unit and nonresidential floorspace per building in the precinct) into a synthesized, disaggregate population of resident persons, households and jobs, by integrating variables from two datasets with different spatial scale. The procedure presented is a prototype that could be improved with further work in several ways. A first improvement is to generalize and automate the procedure. The current prototype still has several manual steps in its workflow. These will be automated in the next version of the procedure.

Second, it would be very desirable to have a bi-level representation of the transportation network: the "macro" network used in GTAModel, and a "micro", much more detailed network representation of the network within the precinct and its immediate surroundings. This micro network would include walk and bicycle links and paths in addition to road and transit. GTAModel-generated trips could be assigned to this micro network to provide very detailed representations of actual paths taken through the precinct by mode and time of day (possibly down to the level of trips originating and ending at individual buildings within the precinct; persons walking to and from individual transit stops, etc.). Developing and modeling this local micro network will be undertaken in the next phase of the work. Tied directly to the micro modeling of trips within the precinct is the use of advanced visualization to dynamically display these trips traveling through the multi-modal local network. The University of Toronto is partnered with Esri Canada to work on this sort of detailed visualization within its "iCity Urban Informatics" project.

Finally, while GTAModel runs very quickly by current industry standards, for sketch planning purposes it would be very desirable if the transportation impacts for a given precinct design could be generated in essentially "real time." At least three avenues for future research to address this issue exist:

1. For GTAModel, the computational bottleneck is the need to use conventional road and transit assignment algorithms, which take $90-95 \%$ of the total model system run time to execute. For sketch planning purposes a much faster, probably much more approximate network assignment model would be very desirable.

2. It would be possible to run GTAModel many times (hundreds or more) across a very wide range of scenarios and then to construct a regression-based meta-model based the GTAModel run outputs that predicts trips to, from and within the precinct for a given scenario without needing to 
run the full GTAModel model system.

3. Some form of "pivot-point" procedure might be developed in which a base GTAModel model system run for the region without the precinct development is used as the base. Incremental changes in travel generated by introduction of a given precinct design would then be estimated.

\section{Acknowledgements}

The research reported in this paper was supported by an Ontario Research Fund Research Excellence Round 7 grant, and a Natural Sciences and Engineering Research Council Discovery grant. Data for the empirical study were generously provided by Waterfront Toronto; a special thanks to Michael Wolfe and Alex Mereu for making this possible. The contributions to the work by James Vaughan and Brendan Reilly from the University of Toronto Travel Modelling Group are gratefully acknowledged. 


\section{References}

Beckman, R. J., Baggerly, K. A., \& McKay, M. D. (1996). Creating synthetic baseline populations. Transportation Research Part A: Policy and Practice, 30(6), 415-429.

Becker, U. J., Schneider, R., \& Schwartzmann, R. (1991). Transportation planning: Microscopic approach. In M. Papageorgiou (Ed.), Concise encyclopedia of traffic and transportation systems (pp. 569574). Oxford, UK: Pergamon Press.

Brand, D., \& Manheim, M. L. (Eds.) (1973). Proceedings of the conference on urban travel demand forecasting. Special report 143. Williamsburg, Virginia, December 3-7, 1972. Retrieved from http:// onlinepubs.trb.org/Onlinepubs/sr/sr143/sr143.pdf

Deming, W. E., \& Stephan, F. F. (1940). On a least squares adjustment of a sampled frequency table when the expected marginals are known. The Annals of Mathematical Statistics, 11(4), 427-444.

Diogu, W. (2019). Towards the implementation of an activity-based travel demand model for emerging cities: Integrating TASHA and MATSim (master's thesis). Department of Civil \& Mineral Engineering, University of Toronto, Toronto, Ontario.

DMG. (2018). TTS 2016 data guide. Toronto: Data Management Group, University of Toronto Transportation Research Institute. Retrieved from http://dmg.utoronto.ca/pdf/tts/2016/2016TTS_ DataGuide.pdf

Farooq, B., Bierlaire, M., Hurtubia, R., \& Flötteröd, G. (2013). Simulation based population synthesis. Transportation Research Part B, 58, 243-263.

Geman, S., \& Geman, D. (1984). Stochastic relaxation, Gibbs distribution, and the Bayesian restoration of images. IEEE Transactions of Pattern Analysis and Machine Intelligence, 6(6), 721-741.

Hammadi, A. (2020). Modelling transportation system impacts of housing supply dynamics (doctoral dissertation). Department of Civil \& Mineral Engineering, University of Toronto, Toronto, Ontario.

Hao, J. (2009) TASHA-MATSim integration and its application in emissions modelling. (master's thesis). Department of Civil \& Mineral Engineering, University of Toronto, Toronto, Ontario.

Hensher, D. A., \& Button, K. J. (2000). Introduction. In D. A. Hensher, \& K. J. Button (Eds.), Handbook of transport modelling (pp. 1-33). Oxford, UK: Pergamon Press.

Horowitz, A. J. (2005). Tests of a family of trip table refinements for long-range, quick-response travel forecasting. Transportation Research Record, Journal of the Transportation Research Board, 1921, 19-26.

ITE. (2017). Trip generation manual, $10^{\text {th }}$ edition. Washington, DC: Institute of Transportation Engineers.

Kaplan, M. P., Gur, Y., \& Vyas, A. D. (1984). Sketch-planning model for urban transportation policy analysis. Transportation Research Record, 952, 32-39.

Koppelman, F. S. (1975). Travel prediction with models of individual choice behavior. Retrieved from https://dspace.mit.edu/handle/1721.1/27389

Martin, W. A., \& Mcguckin, N. A. (1998). Travel estimation techniques for urban planning (Planning and Administration No. 365). Chicago: Barton-Aschman Associates, Inc.

Miller, E. J. (2020). Chapter 2: Travel demand models, the next generation: Boldly going where no-one has gone before. In K.G. Goulias \& A.W. Davis (Eds.), Mapping the travel behavior genome: The role of disruptive technologies, automation and experimentation (pp. 29-46). Amsterdamn: Elsevier.

Miller, E. J., \& Roorda, M. J. (2002). A prototype model of household activity/travel scheduling. Transportation Research Record, Journal of the Transportation Research Board, 1831, 114-121.

Miller, E. J., Roorda, M. J., \& Carrasco, J. A. (2005). A tour-based model of travel mode choice. Transportation, 32(4), 399-422.

Moeckel, R. (2018). Integrated transportation and land use models. Munich: Technical University of Munich. 
Morlok, E. K. (1978). Introduction to transportation engineering and planning. New York: McGraw-Hill. Müller, K., \& Axhausen, K. W. (2010). Population synthesis for microsimulation: State of the art. Paper presented at the Institute for Economic Research's $10^{\text {th }}$ Swiss Transport Research Conference (STRC), September 1-4, Ascona, Switzerland.

Ortùzar, J. D., \& Wilumsen., L. (1990). Modelling transport. Hoboken, NJ: John Wiley \& Sons.

Roorda, M. J., Miller, E. J., \& Nurul Habib, K. (2008). Validation of TASHA: A 24-hour activity scheduling microsimulation mode. Transportation Research A, 42, 360-375.

Roorda, M. J., \& Miller, E. J. (2006). Assessing transportation policy using an activity-based microsimulation model of travel demand. (Winner, ITE past presidents' award 2006). ITE Journal 76, 16-21.

Schneider, R. J., Hu, L., \& Stefanich, J. (2019). Development of a neighborhood commute mode share using nationally available data. Transportation, 46(3), 909-929.

Sosslau, A. B., Hassam, A. B., Carter, M. M., \& Wickstorm, G. V. (1978). Quick-response urban travel estimation techniques and transferable parameters: User's guide (Techichal report No. 186,187). Wheaton, MD: Comsis Corporation.

Statistics Canada. (2019). 2016 census of population (Canada) public use microdata file (PUMF): Individuals file. Study documentation. Kingston, Ontario: Data Services, Queen's University.

WSP. (2018). Lower Yonge Precinct. Municipal class environmental assessment study. Toronto: Waterfront Toronto and the City of Toronto.

Zhuge, C., Li, X., Ku, C.-A., Gao, J., \& Zhang, H. (2017). A heuristic-based population synthesis method for micro-simulation in transportation. KSCE Journal of Civil Engineering, 21(6), 23732383.

Zhang, L., Chang, G.-L., Zhu, S., Xiong, C., Du, L., Mollanejad, M., \& Mahapatra, S. (2013, June). Integrating an agent-based travel behavior model with large-scale microscopic traffic simulation for corridor-level and subarea transportation operations and planning applications. Journal of Urban Planning and Development, 139(2), 94-103. 